7-7-2014

\title{
Fault Detection in Railway Track Using Piezoelectric Impedance
}

Matthew D. Cremins

uconn, matthew.cremins@uconn.edu

\section{Recommended Citation}

Cremins, Matthew D., "Fault Detection in Railway Track Using Piezoelectric Impedance" (2014). Master's Theses. 630. https://opencommons.uconn.edu/gs_theses/630

This work is brought to you for free and open access by the University of Connecticut Graduate School at OpenCommons@UConn. It has been accepted for inclusion in Master's Theses by an authorized administrator of OpenCommons@UConn. For more information, please contact 


\title{
Fault Detection in Railway Track Using Piezoelectric Impedance
}

\author{
Matthew Cremins \\ B.S., University of Connecticut, 2013
}

\author{
A Thesis \\ Submitted in Partial Fulfillment of the \\ Requirements for the Degree of \\ Master of Science \\ at the \\ University of Connecticut
}

2014 


\begin{abstract}
APPROVAL PAGE
Master of Science Thesis

Fault Detection in Railway Track Using Pieznelectric Impedancc
\end{abstract}

Presented by

Matthew Cremins, B.S.

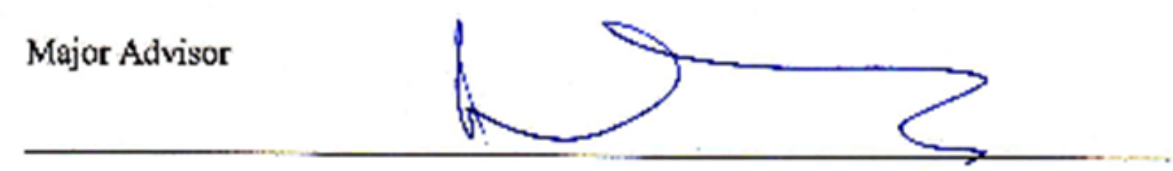

Prof. Jiong Tang
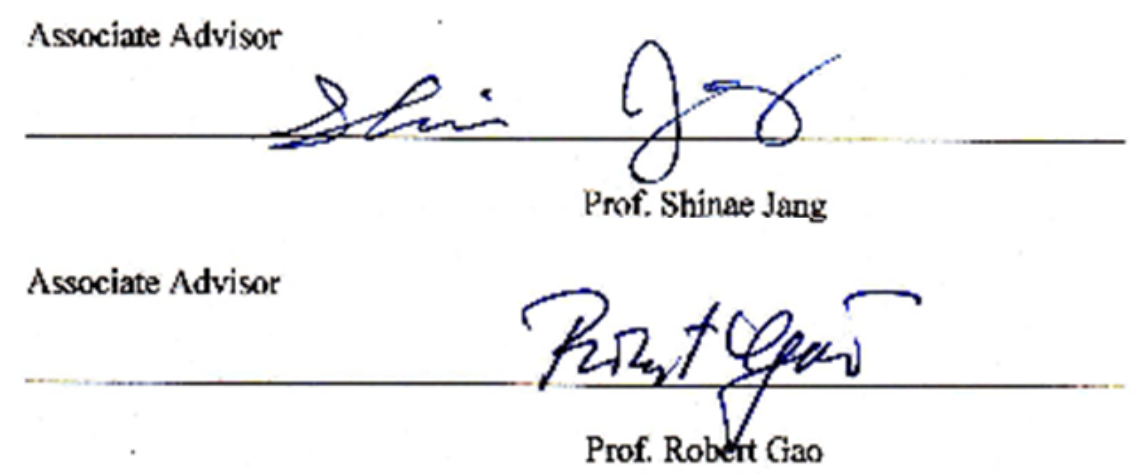

University of Connecticut

2014

ii

ald 


\section{ACKNOWLEDGEMENTS}

I would like to thank my advisor Dr. Jiong Tang for his unwavering encouragement and inspiration throughout both my undergraduate and graduate studies. Under his tutelage, I learned the value of hard work, patience, and perseverance.

I would like to thank Dr. Shinae Jang, Dr. Robert Gao, and Dr. Brice Cassenti for their teachings throughout my studies and for reviewing my defense.

I would like to thank my lab mate and Ph.D. student mentor Qi Shuai, who has been there for me since the first day I entered the lab as an undergraduate; from teaching me core theory, to aiding in my experimental setups. I look forward to seeing all of the great things he will accomplish.

I would like to thank my lab mates Kai Zhou, Ted Diehl, Jiawen Xu, Pei Cao, Shengli Zhang, David Yoo, Shilong Li, Yuan Yuan, and Arun Hedge, all of whom have made the lab an engaging and exciting place to learn.

I would like to thank John Kocur and his team at Sperry Rail Services for their help in arranging the experimental analysis of this thesis.

I would like to thank my parents, Robert and Kathy Cremins, who have loved and supported me for the past twenty-three years, and who have always believed in me. 


\section{TABLE OF CONTENTS}

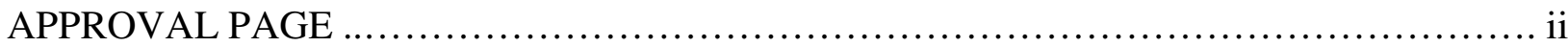

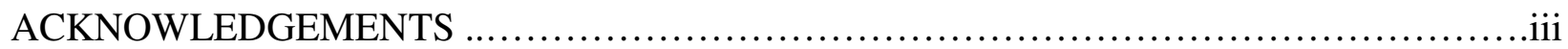

TABLE OF CONTENTS ...................................................................

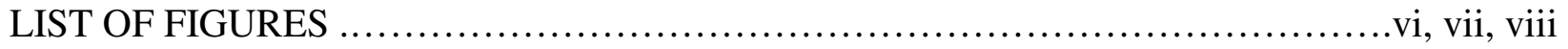

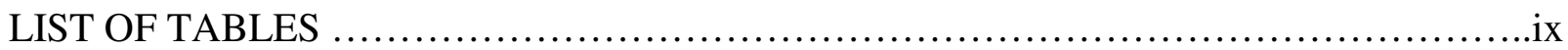

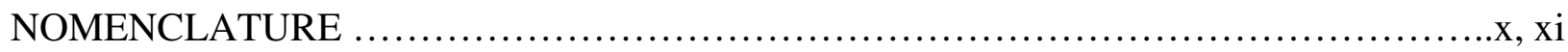

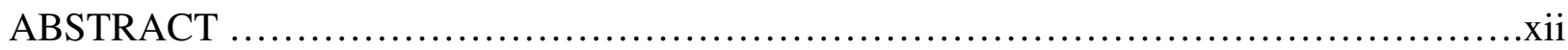

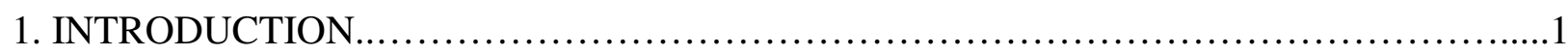

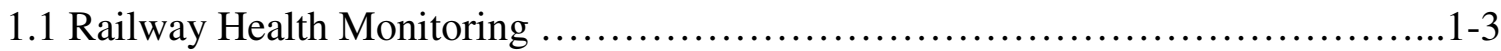

1.2 Piezoelectric Transducers ....................................................

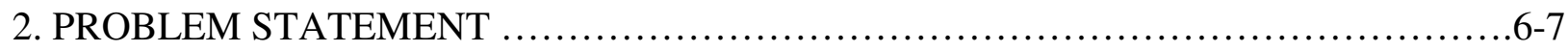

3. RESEARCH OBJECTIVES AND APPROACHES .................................. $7-8$

4. RAILWAY-TRANSDUCER THEORIZATION ................................... $8-19$

4.1 Transducer-Structure Interaction Modeling ..................................8-13

4.2 Impedance Approach for Damage Detection................................14-16

4.3 Inductive Circuitry Enhancements........................................17-19

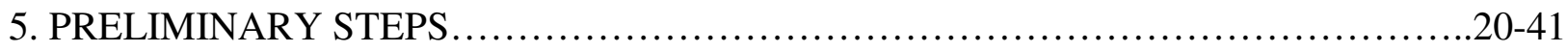

5.1 Fixed-Fixed Aluminum Strip Beam..........................................20-29

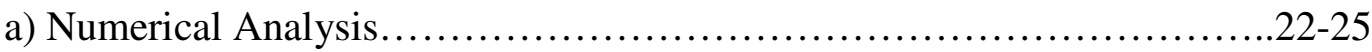

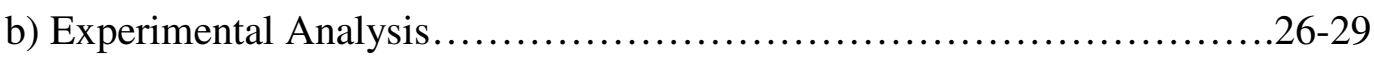




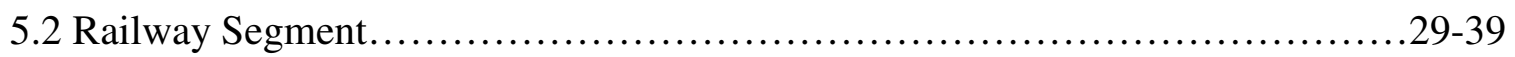

a) Experimental Analysis............................................... $31-34$

b) Finite Element Analysis...............................................34-39

5.3 Stainless Steel Beam........................................................39-41

6. RAILWAY PROOF OF CONCEPT ................................................42-51

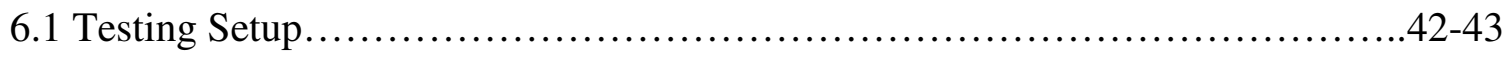

6.2 Normalized Relative Difference Outlier Analysis..............................44-46

6.3 Experimental Analysis..................................................... $46-51$

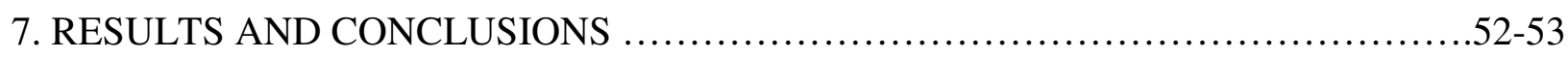

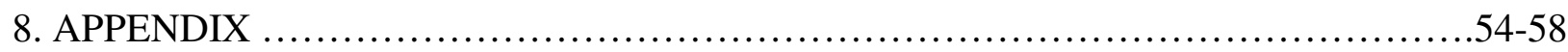

8.1 Winkler Foundation Derivation...................................................

8.2 Inductance Tuning Formulation..........................................55-56

8.3 Aluminum Strip Beam Frequency Comparison...................................57

8.4 Finite Element Model Trials...............................................58

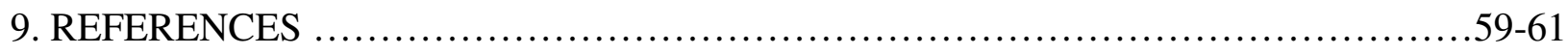




\section{LIST OF FIGURES}

Fig. 1 Piezo Transducer Bonded to Structure...................................... 14

Fig. 2(a) Current RC Method...................................................... 17

Fig. 2(b) Proposed RLC Method.................................................. 17

Fig. 3 Experimental Setup......................................................20

Fig. 4 Agilent 5670A Signal Analyzer.............................................21

Fig. 5 RLC Breadboard Circuit......................................................21

Fig. 6(a) RC Circuit Admittance.....................................................23

Fig. 6(b) RLC Circuit Admittance.................................................23

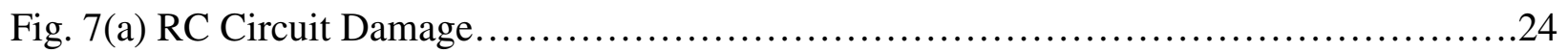

Fig. 7(b) RLC Circuit Damage..................................................24

Fig. 8(a) RC Circuit Admittance................................................... 25

Fig. 8(b) RLC Circuit Admittance.................................................. 25

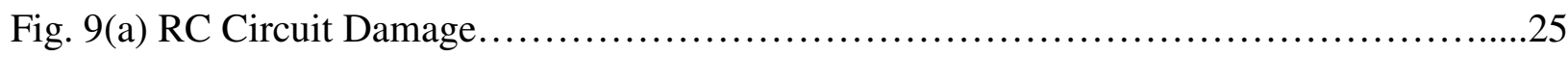

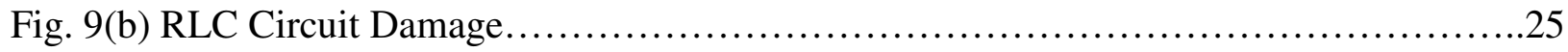

Fig. 10(a) RC Circuit Admittance.................................................... 26

Fig. 10(b) RLC Circuit Admittance................................................26

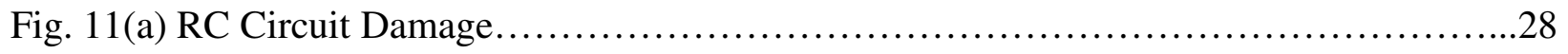

Fig. 11(b) RLC Circuit Damage..................................................28

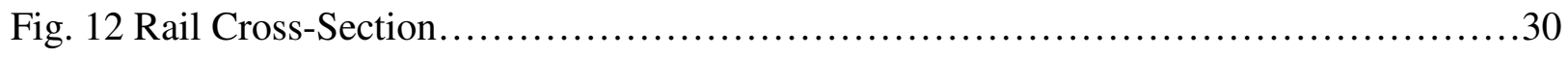

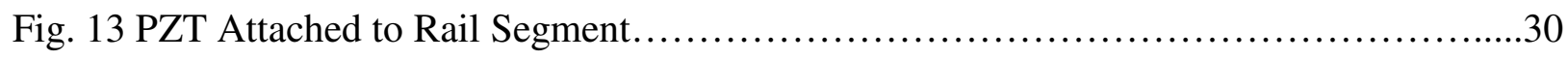




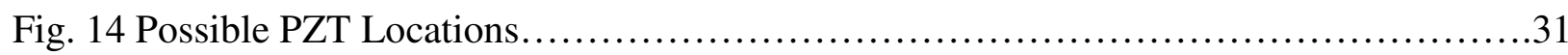

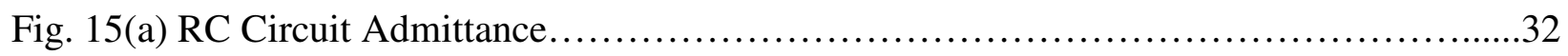

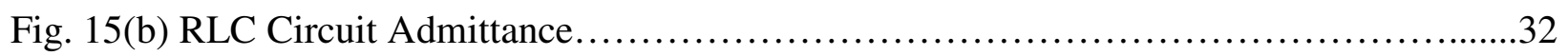

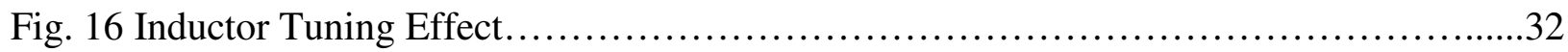

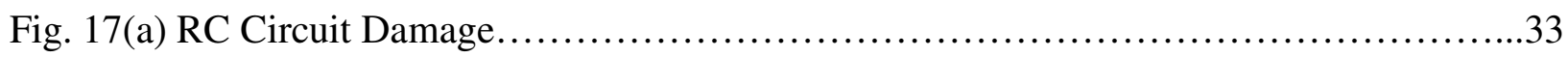

Fig. 17(b) RLC Circuit Damage..................................................... 33

Fig. 18(a) RC Circuit Damage.......................................................... 34

Fig. 18(b) RLC Circuit Damage..................................................... 34

Fig. 19(a) RC Circuit Damage........................................................ 34

Fig. 19(b) RLC Circuit Damage.................................................. 34

Fig. 20 Finite Element Model................................................... 35

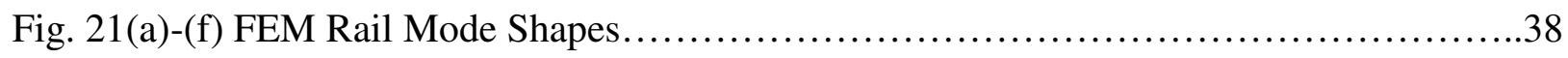

Fig. 22 Beam Lab Setup.......................................................40

Fig. 23 Power Amplifier........................................................40

Fig. 24 Experimental Admittance Curves............................................41

Fig. 25 System Configuration.....................................................41

Fig. 26(a)-(d) Experimental Setup on Test Rail....................................42

Fig. 27 Normalized Relative Difference Illustration..................................45

Fig. 28(a) RC Circuit Admittance................................................ 47

Fig. 28(b) RLC Circuit Admittance................................................47

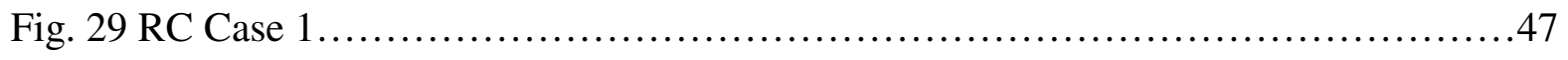

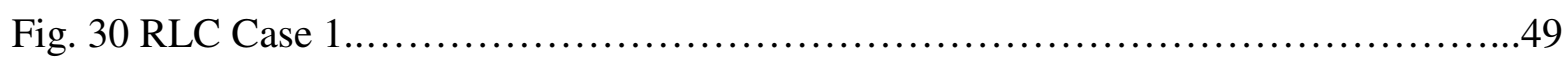

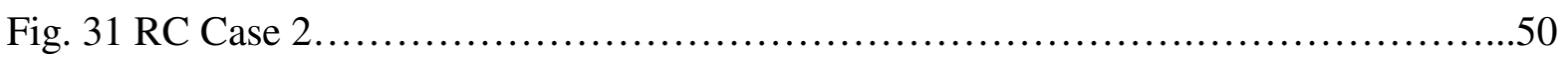




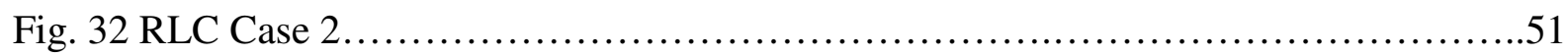




\section{LIST OF TABLES}

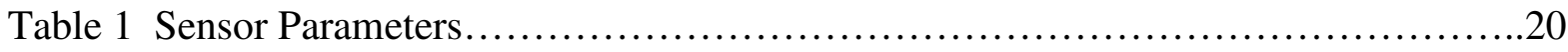

Table 2 Rail Dimensions.................................................... 30

Table 3 PZT Parameters......................................................... 30

Table 4 Finite Element Accuracy Comparison......................................36

Table 5 Natural Frequency Comparison........................................ 37

Table 6 RC Case 1 NRD Values................................................ 47

Table 7 RLC Case 1 NRD Values..............................................49

Table 8 RC Case 2 NRD Values....................................................

Table 9 RLC Case 2 NRD Values..................................................... 


\section{NOMENCLATURE}

Subscripts 'b', 'r' and 'p' indicate beam, rail, and piezo transducer variables, respectively.
A
Cross sectional area
$\mathrm{C}_{\mathrm{p}}$
Piezo transducer capacitance
c
Modal Damping
D
Electrical charge per area
E
Young's modulus
E
Electric field
Strain
F
Force term
g
Damping coefficient
$\Delta \mathrm{H}$
Heavy side step function
I
Moment of inertia
$\mathrm{k}$
Modal stiffness
$\mathrm{k}_{1}$
Cross coupling coefficient
$\mathrm{k}_{2}$
Inverse of capacitance of piezo transducer
$\widehat{\mathrm{k}}_{2}$
Inverse of overall circuit capacitance
L
Circuit inductance
1
Length
$\mathrm{m}$
Modal mass
$\rho$
Density
Q
Charge flow to the piezoelectric patch
q
Generalized mechanical displacement 


$\begin{array}{ll}\mathrm{R} & \text { Total circuit resistance } \\ \mathrm{T} & \text { Kinetic energy } \\ \mathrm{t} & \text { Time } \\ \tau & \text { Stress } \\ \mathrm{U} & \text { Potential energy } \\ \mathrm{V}_{\mathrm{a}} & \text { Voltage across the piezoelectric patch } \\ \mathrm{V}_{\mathrm{i}} & \text { Active voltage input } \\ \mathrm{V}_{\mathrm{o}} & \text { Output voltage } \\ \mathrm{W} & \text { Operating frequency } \\ \mathrm{W}_{\mathrm{n}} & \text { First natural frequency } \\ w & \text { Width } \\ \mathrm{W} & \text { Work term } \\ \widehat{\mathrm{Y}} & \text { Admittance } \\ \widehat{\mathrm{Z}} & \text { Impedance } \\ \varphi & \text { Assumed mode for mechanical displacement } \\ \Psi & \text { Assumed mode for electrical displacement }\end{array}$




\section{ABSTRACT}

In this thesis, piezoelectric transducers are incorporated in an impedance-based damage detection approach for railway track health monitoring. The impedance-based damage detection approach utilizes the direct relationship between the mechanical impedance of the track and electrical impedance of the piezoelectric transducer bonded. The effect of damage is shown in the change of a healthy impedance curve to an altered, damaged curve. Using a normalized relative difference outlier analysis, the occurrences of various damages on the track are determined. Furthermore, the integration of inductive circuitry with the piezoelectric transducer is found to be able to considerably increase overall damage detection sensitivity. 


\section{INTRODUCTION}

\subsection{Railway Health Monitoring}

Over the past decade, the research and implementation of Structural Health Monitoring (SHM) systems has emerged as an important topic in the engineering world. There is an everincreasing need to improve the safety and maintenance of both existing infrastructure and the infrastructure of the future. Today, SHM systems are being utilized in a variety of fields: from high-end defense related platforms, to wind turbines and airframes, to buildings and bridges. One specific area of consideration is the health monitoring of railway tracks to detect track defects. The total market size for rail testing and health monitoring is between $\$ 200-300$ million, and is steadily growing as railway health monitoring becomes a more pressing concern. From 2010 to 2013 alone, the US Federal Railroad Administration reports 6,219 train accidents, with 2,084 $(33.5 \%)$ of them caused directly by track defects. In addition to track defects, it is vital to detect the presence of harmful foreign objects on the track to prevent terrorist attacks. Because of these omnipresent threats, there is a need for a health monitoring system to detect the presence of damage on railways in an efficient and robust manner. The system needs to be capable of providing real-time health monitoring of the track, and it needs to be cost-effective with minimum human involvement. 
Since the mid 1800's, railroad operators have used the hammer impact test to evaluate the presence of damage on railways. However, as technology progressed, this primitive test gave way to a variety of non-destructive (NDE) damage detection methods; the first being magnetic induction, created by Elmer Sperry in 1927. Today, the most common form of railway damage detection is in-situ ultrasonic waves [1]. This is a direct result of a 1988 revision to "Specification for Steel Rails" by The American Railway Engineering Association (AREA) that requires in-situ ultrasonic waves to be used monthly to monitor all US steel railways. The basic principle behind ultrasonic detection is that a beam of ultrasonic energy is sent into the rail from a roller search truck (RSU) and reflected, and the scattered energy is gathered using a collection of transducers contained in fluid-filled wheels that roll behind the RSU. The amplitude and timing of the reflections indicate the integrity of the rail [2]. Ultrasonic detection is widely used primarily because of its effectiveness in screening the railway on the component level. Other component level methods include acoustic emission, where an acoustic sensor is attached to the inside of the train or truck wheel [3], and radiography. The major advantage of each of these methods is the accuracy to which they can detect the type and severity of damage. However, these methods require a trained professional to continually operate the equipment on the railway, which can be very costly and hinder regular railway operations. In addition, none of these methods can detect damage in real-time, meaning that the operator does not know if the track has been damaged until the train or truck performing the test passes over a damaged spot. 
As a response to this challenge, several railway damage detection methods have been proposed that have the ability to collect real-time data on the health of the track, in order to instantly detect damage and report it to the operator. These methods use the railway's vibration characteristics in conjunction with numerical techniques to detect damage. In most cases, these methods are also more cost effective, because they do not need an operator to continuously operate the equipment. The most common method is guided elastic waves, where energy either from an actuator or the train itself produces waves that propagate along the track until they reach a broken rail. Guided elastic waves have been researched extensively [4-5], and have been implemented in several forms onto operating railways [6]. Although guided waves have proved to be a promising solution for railway health monitoring, the major challenge is that the wave deteriorates in strength as it propagates along the track, especially when the wave attempts to cross the joints of separate rail segments. As a result, it is generally difficult to predict the severity of damage.

\subsection{Piezoelectric Transducers}

Alternatively, an impedance-based SHM system utilizing piezoelectric transducers (PZT) is a promising solution to satisfy the need to accurately detect damage in real-time on rail tracks. A piezoelectric transducer is a piece of polarized material with electrodes attached to two of its opposite faces. It exhibits what is called the piezoelectric effect; a reversible process where electricity is generated as a result of an applied mechanical force, and mechanical strain is generated as a result of an applied voltage. Piezoelectric transducers were originally made of quartz crystals, but modern transducers are made of ceramic materials, such as barium titanate 
and lead zirconate titanate. Today, these ceramic transducers are used for SHM in a wide variety of industries, including the defense, aerospace, and manufacturing domains. Upon bonding the transducer to a monitored host structure, the piezoelectric effect creates a two-way electromechanical coupling between the transducer and host. Because of this two-way electromechanical coupling characteristic, piezoelectric transducers have the ability to both actuate the host structure and sense the response. For a railway application, this is incredibly useful, because the transducers can collect real-time health information for the operator without needing a separate source of actuation. When coupled with the impedance method for damage detection (to be discussed), piezoelectric transducers collect responses that are harmonic in nature, meaning that they have the potential to detect both the magnitude and location of damage. A sufficient amount of transducers can be determined in order to accurately detect the presence of damage on a component level throughout the rail.

Leveraging the advantage of piezoelectric transducers to accurately collect structural health information in real time, there is a great opportunity to implement an impedance-based SHM system utilizing piezoelectric transducers that would supplement the current ultrasonic approach to railway health monitoring. The approaches complement each other well for two main reasons:

\section{Each method enhances the other method:}

Piezo transducers can collect real time railway health monitoring information, where ultrasonic testing can only monitor the rail when the RSU is in operation, and harmful damage 
may both occur and cause an accident between the times when the RSU inspected the track. On the other hand, ultrasonic testing can accurately detect the type of damage (detail fractures, split heads, transverse fissures, external harmful foreign objects, etc.) and severity of damage, which gives the operator information on if the rail should be replaced, and if so, when it should be replaced. Piezo transducers do not have the present capability to detect the type of damage. When the methods are combined however, a railway operator always has knowledge if there is damage present on the track, and at any time can determine what type of damage is present. When a transducer detects damage, the railway can halt normal train operations, run an RSU over the damaged rail section, and determine if the damage is a threat to passenger safety.

2. The combined method reduces yearly inspection costs increases revenue for the railway operator:

An impedance-based SHM system utilizing piezoelectric transducers represents a low cost, low maintenance solution to railway health monitoring. Simple transducer plates cost between $\$ 10$ and $\$ 50$ per plate (for reference, the transducer used in the following railway experimental analysis costs \$14) and require one-time installation. The one-time capital cost plus a periodic maintenance cost is an excellent alternative to the recurring cost of a trained operator to run the RSU over the track. The roughly 200,000 miles of total rail track in the US require on average a bi-monthly ultrasonic inspection. Each hour of inspection costs between $\$ 200$ and $\$ 300$, and the RSU runs on an average speed of 30mph. This equates to around 160,000 inspection hours per year, or $\$ 32$ million of inspection costs alone per year. 
With the combined system, one would only need to run the RSU after the presence of damage has been detected. As a result, the inspection hours on the track would drastically be reduced, which would significantly cut the yearly ultrasonic inspection cost. In addition, railway operators would not have to regularly stall regular train operations while the RSU runs over the track. Instead, operators would only stop normal train flow when damage is detected. This increases revenues for the railway operator, especially on subway lines where RSU's are run over the tracks weekly, and trains are constantly needed to move high amounts of passengers.

The proposed combination of methods addresses the need for a real-time, accurate railway health monitoring, and is financially advantageous to both the health monitoring service provider and rail operator. Because of this, an impedance-based SHM system utilizing piezoelectric transducers is a feasible commercialization opportunity, provided that the system can indeed accurately detect the presence of damage on the railway.

\section{PROBLEM STATEMENT}

Current and developing methods for railway health monitoring have been outlined above. Among them, the in-situ ultrasonic wave approach is the most widely accepted form of railway health monitoring because of its ability to accurately discern the type and severity of damage on track. However, neither ultrasonics nor any less prominent method solves the need for a health monitoring system to detect the presence of damage or harmful foreign objects on railways in real-time. On the other hand, an impedance-based SHM system utilizing piezoelectric transducers has the potential to solve this need, and could effectively supplement the current ultrasonic approach. 
Though the impedance-based approach is promising, it has never before been implemented on a full scale, in-use railway track. There are concerns of the PZT's ability to detect damage at various railway modes, and the sensitivity to which the damage can be detected. The traditional impedance approach often suffers from low signal to noise ratio in the high frequency range, and the structural damping of the railway further decreases the signal to noise ratio. The feasibility of the impedance method needs to be proven on a full scale, in-use railway track, and a method needs to be devised that can amplify the signal to noise ratio and resulting sensitivity of the impedance measurement.

\section{RESEARCH OBJECTIVES AND APPROACHES}

Although the core theorization behind the impedance approach in relation to piezoelectric transducers has been well documented, insofar as I am aware, there is no documentation of direct application of this method to railway health monitoring in the field. In this thesis, the impedancebased damage detection approach will be directly applied to a full scale, in-use railway track as a proof of concept. The mathematical relationship between the bonded PZT and rail will be derived, and an inductive circuitry enhancement to increase damage detection sensitivity will be incorporated into the derivation. Several preliminary investigations will be performed to assess the viability of the damage detection method in a controlled lab setting. A MatLab program will be developed based on the derived theory that will provide a numerical comparison to the initial investigation, and a finite element analysis on the rail cross-section will be created. Upon promising results from the investigations, the damage detection method will be applied to a full scale, in-use rail track. Applying damaging conditions to the railway will reveal whether or not 
the PZT has the ability to clearly detect structural changes in the rail. Inductive circuitry will also be integrated to increase sensitivity, and the overall performance improvement will be measured. The objectives of this research are summarized as follows:

To implement the impedance-based damage detection approach on a full scale in-use railway track, and successfully detect damage on the track.

To experimentally verify that inductive circuitry increases sensitivity to smallsized damage on the rail track.

\section{THEORY}

\subsection{Transducer-Structure Interaction Modeling}

Hamilton's principle is a formulation of the principle of least action, which states that a particle system's path between two points in space is one where the action integral is stationary regardless of path variation. Hamilton's principle considers the entire motion of a system between times $t_{1}$ and $t_{2}$, with infinite degrees of freedom. Since deformable bodies contain many degrees of freedom and occupy continuous space, Hamilton's principle is useful in defining the state of the system by functions of time and space. The principle can be used to derive the equations of motion for a dynamic system, such as a railway. The extended Hamilton Principle for a railway is given by:

$$
\int_{\mathrm{t} 1}^{\mathrm{t} 2}\left[\delta \mathrm{W}_{\mathrm{e}}+\delta \mathrm{T}-\delta \mathrm{U}\right] \mathrm{dt}=0
$$


where $\mathrm{T}, \mathrm{U}$ and $\mathrm{W}_{\mathrm{e}}$ are, respectively, the kinetic energy of the railway, the potential energy of the railway, and the external work done on the railway. Perfect bonding is assumed in the analysis, and the rail's transversal vibration is considered. Upon bonding the PZT to the railway, the structure now becomes an integrated system [7], and Hamilton's Principle changes to:

$$
\int_{\mathrm{t} 1}^{\mathrm{t} 2}\left[\delta \mathrm{W}_{\mathrm{v}}+\delta \mathrm{T}-\delta \mathrm{U}_{\mathrm{r}}-\delta \mathrm{U}_{\mathrm{p}}\right] \mathrm{dt}=0
$$

where $T, \mathrm{U}_{\mathrm{r}}, \mathrm{U}_{\mathrm{p}}$ and $\delta \mathrm{W}_{\mathrm{v}}$ are, respectively, the kinetic energy of the integrated system, the potential energy of the railway, the elastic and electrical energy of the piezoelectric patch, and the virtual work. Each term in Hamilton's principle is modal dependent, meaning that their value will change with a change in applied mode. To discretize Hamilton's principle, the assumed mode method below is used:

$$
\mathrm{w}(\mathrm{x}, \mathrm{t})=\sum_{\mathrm{i}=1}^{\mathrm{N}} \varphi(\mathrm{x}) \mathrm{q}(\mathrm{t})
$$

where $\varphi$ is the eigenfunction of the railway with no piezo transducer attached, and $q$ is the generalized mechanical displacement. In general, the equation is applied to $\mathrm{N}$ assumed modes, but for this study, only a single-mode model is assumed $(\mathrm{N}=1)$. The railway can be considered a continuous system with a uniform cross-sectional area, and the assumed mode method transforms the continuous system into a discrete system. The method is used to form a multidegree of freedom approximation for the kinetic energy $\mathrm{T}$, transforming the conventional equation below:

$$
\mathrm{T}=\frac{1}{2} \int_{0}^{\operatorname{lr}} \rho \mathrm{A}\left(\frac{\partial \mathrm{q}}{\partial \mathrm{t}}\right)^{2} \mathrm{dx}
$$

into a single degree of freedom approximation:

$$
\mathrm{T}=\frac{1}{2} \mathrm{~m} \mathrm{q}^{2}
$$

The kinetic energy of the integrated system is a summation of the kinetic energy of the railway and the kinetic energy of the piezoelectric patch: 


$$
\mathrm{T}=\mathrm{T}_{\mathrm{r}}+\mathrm{T}_{\mathrm{p}}=\frac{1}{2} \mathrm{~m}_{\mathrm{r}} \dot{\mathrm{q}}^{2}+\frac{1^{\cdot}}{2} \mathrm{~m}_{\mathrm{p}} \dot{\mathrm{q}}^{2}
$$

where $\mathrm{m}_{\mathrm{r}}$, and $\mathrm{m}_{\mathrm{p}}$ are the modal mass of the railway and the piezo patch, respectively, and are given by:

$$
\begin{aligned}
& \mathrm{m}_{\mathrm{r}}=\int_{0}^{\mathrm{lb}} \rho_{\mathrm{r}} \mathrm{A}_{\mathrm{r}} \varphi^{2} \mathrm{dx} \\
& \mathrm{m}_{\mathrm{p}}=\int_{0}^{\mathrm{lb}} \rho_{\mathrm{p}} \mathrm{A}_{\mathrm{p}} \Delta \mathrm{H} \varphi^{2} \mathrm{dx}
\end{aligned}
$$

$\Delta \mathrm{H}$ is the heavy side step function. It is used because the PZT can be placed anywhere along the railway, and the resulting equivalent mass of the system is location dependent. The heavy side step function is defined as:

$$
\Delta H=H\left(x-x_{1}\right)-H\left(x-x_{r}\right)
$$

where $x_{1}$ and $x_{r}$ are the left and right end of the piezoelectric patch, respectively. The potential energy of the railway is found similarly by transforming:

$$
\mathrm{U}_{\mathrm{r}}=\frac{1}{2} \int_{0}^{\operatorname{lr}} \mathrm{EI}\left(\frac{\partial^{2} \mathrm{q}}{\partial^{2} \mathrm{x}}\right)^{2} \mathrm{dx}
$$

into:

$$
\mathrm{U}_{\mathrm{r}}=\frac{1}{2} \mathrm{k}_{\mathrm{r}} \mathrm{q}^{2}
$$

Where $\mathrm{k}_{\mathrm{r}}$, the modal railway stiffness, is:

$$
\mathrm{k}_{\mathrm{r}}=\int_{0}^{\mathrm{lr}} \mathrm{E}_{\mathrm{r}} \mathrm{A}_{\mathrm{r}} \dot{\varphi}^{2} \mathrm{dx}=\int_{0}^{\mathrm{lr}} \mathrm{E}_{\mathrm{r}} \mathrm{I}_{\mathrm{r}} \varphi^{2} \mathrm{dx}
$$

$E_{r}$ is the railway's Young's modulus, and $I_{r}$ is the railway's moment of inertia. Turning to the piezoelectric transducer, the Institute of Electrical and Electronics Engineers defines the linear constitutive relation for a piezoelectric material in many forms. A simple form for onedimensional applications is: 


$$
\tau=\mathrm{E}_{\mathrm{p}} \square-\mathrm{h}_{31} \mathrm{D}
$$

(5a)

$$
E=-\mathrm{h}_{31} \square+\beta_{33} \mathrm{D}
$$

where $\tau, \varepsilon, \mathrm{D}$ and $E$ represent the stress, strain, electrical charge per area and electrical field, or the voltage per length along the transverse direction in the piezoelectric patch, respectively, and $E_{p}, h_{31}$ and $\beta_{33}$ are the piezo Young's modulus, piezoelectric constant and dielectric constant of the material. Using the assumed mode method again for the transducer, the electrical displacement of the piezoelectric patch is given as:

$$
\mathrm{D}=\Psi \mathrm{p}
$$

Where $\mathrm{p}$ is the generalized electrical displacement. The elastic and electrical energy of the piezoelectric patch is represented by:

$$
\delta \mathrm{U}_{\mathrm{p}}=\int_{\mathrm{v}}(\tau \delta \square+E \delta \mathrm{D}) \mathrm{dV}
$$

and from the linear constitutive relation, is transformed into:

$$
\begin{aligned}
& \delta \mathrm{U}_{\mathrm{p}}=\int_{\mathrm{v}}\left(\mathrm{E}_{\mathrm{p}} \square-\mathrm{h}_{31} \mathrm{D}\right) \delta \square \mathrm{dV}+\int_{\mathrm{v}}\left(-\mathrm{h}_{31} \square+\beta_{33} \mathrm{D}\right) \delta \mathrm{D} \mathrm{dV} \\
& =\mathrm{k}_{\mathrm{p}} \mathrm{q} \delta \mathrm{q}+\mathrm{k}_{\mathrm{pq}} \mathrm{p} \delta \mathrm{q}+\mathrm{k}_{\mathrm{pq}} \mathrm{q} \delta \mathrm{p}+\mathrm{k}_{\mathrm{pp}} \delta \mathrm{p}
\end{aligned}
$$

where

$$
\begin{aligned}
& \mathrm{k}_{\mathrm{p}}=\int_{0}^{\mathrm{lr}} \mathrm{E}_{\mathrm{p}} \mathrm{I}_{\mathrm{p}} \ddot{\varphi}^{2} \Delta \mathrm{Hdx} \\
& \mathrm{k}_{\mathrm{pp}}=\int_{0}^{\mathrm{lr}} \mathrm{A}_{\mathrm{p}} \beta_{33} \Psi^{2} \Delta \mathrm{Hdx} \\
& \mathrm{k}_{\mathrm{pq}}=\int_{0}^{\mathrm{lr}} \mathrm{F}_{\mathrm{p}} \mathrm{h}_{31} \ddot{\varphi}^{2} \Psi \Delta \mathrm{Hdx}
\end{aligned}
$$


The virtual work on the railway, $\delta \mathrm{W}_{\mathrm{v}}$, is a combination of the external disturbance on the railway, $\delta \mathrm{W}_{\mathrm{m}}$, the railway structural damping value, $\delta \mathrm{W}_{\mathrm{g}}$, and the work done by the voltage across the piezoelectric patch, $\delta \mathrm{W}_{\mathrm{e}}$ :

$$
\begin{aligned}
& \delta \mathrm{W}_{\mathrm{m}}=\mathrm{F}_{\mathrm{m}} \delta \mathrm{q} \\
& \delta \mathrm{W}_{\mathrm{g}}=\mathrm{d} \dot{\mathrm{q}} \dot{\delta} \mathrm{q} \\
& \delta \mathrm{W}_{\mathrm{e}}=\mathrm{F}_{\mathrm{e}} \delta \mathrm{p} \\
& \delta \mathrm{W}_{\mathrm{v}}=\delta \mathrm{W}_{\mathrm{e}}+\delta \mathrm{W}_{\mathrm{m}}-\delta \mathrm{W}_{\mathrm{g}}
\end{aligned}
$$

Where the external force, $\mathrm{F}_{\mathrm{m}}$, the damping, $\mathrm{g}$, and the force from the voltage, are given by:

$$
\begin{aligned}
& \mathrm{F}_{\mathrm{m}}=\int_{0}^{\operatorname{lr}} \hat{\mathrm{F}}(\mathrm{x}, \mathrm{t}) \varphi \mathrm{dx} \\
& \mathrm{g}=\int_{0}^{\operatorname{lr}} \mathrm{c}_{\mathrm{r}} \varphi^{2} \mathrm{dx} \\
& \mathrm{F}_{\mathrm{e}}=\int_{0}^{\operatorname{lr}} \mathrm{V}_{\mathrm{a}} \mathrm{w}_{\mathrm{p}} \Psi \Delta \mathrm{Hdx}
\end{aligned}
$$

Substituting each term back in equation $1 b$ results in:

$$
\begin{gathered}
\left(\mathrm{m}_{\mathrm{r}}+\mathrm{m}_{\mathrm{p}}\right) \ddot{\mathrm{q}}+\mathrm{g} \dot{\mathrm{q}}+\left(\mathrm{k}_{\mathrm{r}}+\mathrm{k}_{\mathrm{p}}\right) \mathrm{q}+\mathrm{k}_{\mathrm{pq}} \mathrm{p}=\mathrm{F}_{\mathrm{m}} \\
\mathrm{k}_{\mathrm{pq}} \mathrm{q}+\mathrm{k}_{\mathrm{pp}} \mathrm{p}=\mathrm{F}_{\mathrm{e}}
\end{gathered}
$$

The electrical displacement is assumed to be independent of spatial conditions, or $\Psi=1$ and the following relationships are assumed:

$$
\begin{aligned}
& \mathrm{D}=\mathrm{Q} /\left(w_{\mathrm{p}} 1_{\mathrm{p}}\right) \\
& \mathrm{m}=\mathrm{m}_{\mathrm{r}}+\mathrm{m}_{\mathrm{p}} \\
& \mathrm{k}=\mathrm{k}_{\mathrm{r}}+\mathrm{k}_{\mathrm{p}} \\
& \mathrm{k}_{1}=\mathrm{k}_{\mathrm{pq}} / w_{\mathrm{p}} 1_{\mathrm{p}} \\
& \mathrm{k}_{2}=\mathrm{k}_{\mathrm{pp}} /\left(w_{\mathrm{p}} 1_{\mathrm{p}}\right)^{2}
\end{aligned}
$$


Substituting these values into equations $7 \mathrm{a}, 7 \mathrm{~b}$ results in the following governing equations of motion for the coupled railway:

$$
\begin{aligned}
& \mathrm{m} \ddot{\mathrm{q}}+\mathrm{g} \dot{\mathrm{q}}+\mathrm{kq}+\mathrm{k}_{1} \mathrm{Q}=\mathrm{F}_{\mathrm{m}} \\
& \mathrm{k}_{2} \mathrm{Q}+\mathrm{k}_{1} \mathrm{q}=\mathrm{V}_{\mathrm{a}}
\end{aligned}
$$

where $\mathrm{m}$ is the equivalent mass, $\mathrm{g}$ is the damping coefficient, $\mathrm{k}$ is the equivalent stiffness, $\mathrm{q}$ is the mechanical displacement, $F_{m}$ is the external disturbance force, $k_{2}$ is the inverse of the capacitance of the system, $\mathrm{k}_{1}$ is the cross coupling coefficient, $\mathrm{Q}$ is the charge across the piezoelectric patch, and $\mathrm{V}_{\mathrm{a}}$ is the applied voltage on the piezoelectric patch. In the following analysis, $F_{m}$ is assumed to be zero, meaning that there is no external force applied. These two equations illustrate how the structure's mechanical displacement and the piezoelectric charge flow are interdependent, creating a two-way electro-mechanical coupling effect.

It is important to note that up to this point, rail section boundary conditions and the force of the ground on the railway are neglected. This is because both the rail section boundary conditions and the force from the ground are difficult to properly define. The boundary conditions cannot be accurately assumed using a traditional boundary condition (fixed-fixed, free-free, etc.) because each rail section is connected with joints of various sizes and shapes. The force from the ground on the railway is non-uniform because wood tiles, gravel, dirt, and concrete all lay below the railway in different locations. A typical foundation model, such as a Winkler model where there is an assumed linear force deflection relationship, or the more generalized elastic model, can be used to approximate these conditions, as shown in section 8.1 in the Appendix, but they are not sufficient to describe the force deflection relationship on the railway from the ground. The complexities in boundary conditions and ground forces lead to 
challenges in both numerical analysis and finite element modeling (topics to be covered), but the core equations of motion remain intact, and can be used to derive the relationship between the railway's mechanical impedance and the piezoelectric impedance.

\subsection{Impedance Approach for Damage Detection}

The impedance-based damage detection method directly relates the electrical impedance of the piezoelectric transducer attached to a structure ( ) to the mechanical impedance of the structure itself ( $\quad$ ) and the electrical impedance of the stand-alone piezoelectric transducer ( ). From a material property standpoint, these three impedance quantities are related by the equation below:
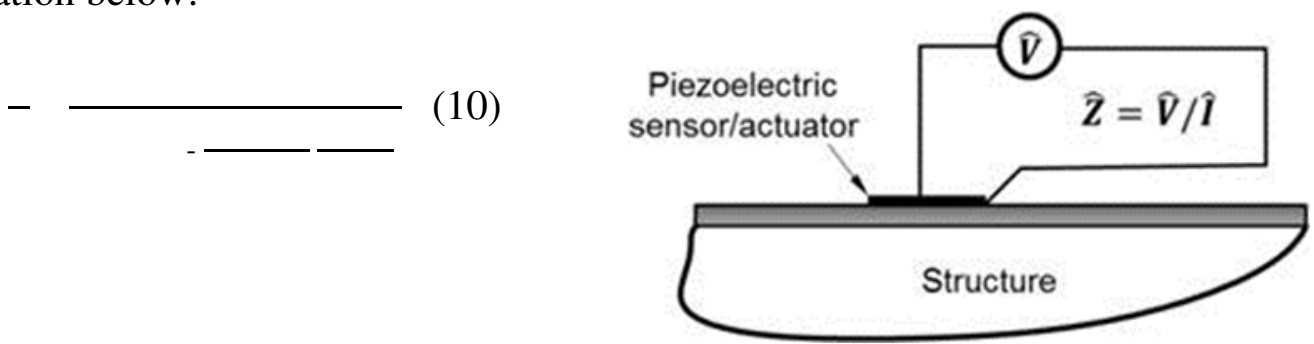

Figure 1. Piezo Transducer Bonded to Structure

Where is the capacitance of the piezoelectric transducer, $d_{31}$ is the piezoelectric strain coefficient, and is the invers of the complex Young's modulus. is the static permittivity of the piezoelectric transducer, and the complex permittivity is given as - , where is the permittivity loss factor [8]. Therefore, upon bonding the PZT to a host structure, the PZT can be utilized simultaneously as an actuator to excite the structure and a sensor to collect the impedance information [9]. 
In this research, the electrical admittance of the piezoelectric transducer as it relates to the structural impedance is studied. The electrical admittance of the piezoelectric transducer $(\widehat{\mathrm{Y}})$ is simply the inverse of the electrical impedance, but its measurement is significantly impacted by circuitry dynamics, which makes it more useful for damage detection [9].

The typical circuit to extract piezoelectric admittance information contains a resistor connected in series with the PZT, creating a self-contained sensor with the PZT acting as the circuit capacitor. A sinusoidal voltage frequency sweep is used to drive the PZT, and the resulting current is measured across the resistor to determine the admittance response. For the simple case of the circuit containing a resistor and the transducer connected in series, the applied voltage to the piezoelectric patch, $\mathrm{Va}$, is related to the input voltage, $\mathrm{V}_{\mathrm{i}}$, by the following relationship:

$$
\mathrm{V}_{\mathrm{a}}=-\mathrm{R} \dot{\mathrm{Q}}+\mathrm{V}_{\mathrm{i}}
$$

Under harmonic excitation, the two equations of motion (9a, b), are transferred to the frequency domain. The resulting transfer functions between structural response and external disturbance and between structural response and input voltage are, respectively:

$$
\begin{aligned}
\frac{\overline{\mathrm{q}}}{\overline{\mathrm{F}}_{\mathrm{m}}} & =\frac{\mathrm{Riw}+\mathrm{k}_{2}}{\left(\mathrm{Riw}+\mathrm{k}_{2}\right)\left(-\mathrm{mw}^{2}+\mathrm{igw}+\mathrm{k}\right)-\mathrm{k}_{1}^{2}} \\
\frac{\overline{\mathrm{q}}}{\overline{\mathrm{V}}_{\mathrm{i}}} & =\frac{\mathrm{k}_{1}}{\mathrm{k}_{1}^{2}-\left(\mathrm{R} i \mathrm{w}+\mathrm{k}_{2}\right)\left(-\mathrm{m} \mathrm{w}^{2}+\mathrm{igw}+\mathrm{k}\right)}
\end{aligned}
$$

From the equations of motion, the output voltage measured across the resistor is:

$$
\overline{\mathrm{V}}_{\mathrm{o}}=\left(\overline{\mathrm{V}}_{\mathrm{i}}-\mathrm{k}_{1} \overline{\mathrm{q}}\right) \frac{\mathrm{R}}{\left(\mathrm{R}+\mathrm{k}_{2} / \mathrm{i} \mathrm{w}\right)}
$$

Combining equations (12b) and (12c) results in the electrical admittance of the piezoelectric circuitry: 


$$
\widehat{Y}=\frac{\bar{I}}{\bar{V}_{i}}=\frac{\left(\frac{\bar{V}_{o}}{R s}\right)}{\bar{V}_{i}}=i w \frac{-m w^{2}+i c w+k}{\left(i R w+k_{2}\right)\left(-m w^{2}+i c w+k\right)-k_{1}^{2}}
$$

To clearly see the admittance relationship, the circuitry admittance is normalized with respect to the stand-alone piezoelectric transducer electrical admittance before bonding to the railway. The stand-alone electrical admittance is given as:

$$
\widehat{\mathrm{Y}}_{\mathrm{p}}=\mathrm{iw} / \mathrm{k}_{\mathrm{p}}
$$

And the resulting normalized admittance is:

$$
\frac{\widehat{Y}}{\widehat{\widehat{Y}}_{p}}=\frac{k_{2}\left(-m w^{2}+i c w+k\right)}{\left(i R w+k_{2}\right)\left(-m w^{2}+i c w+k\right)-k_{1}^{2}}
$$

It is worth noting that the imaginary part of the electrical admittance is more sensitive to the temperature variation than the real part because the complex permittivity is temperature sensitive [9]. Because of this, the real part of the admittance is used in the following experiments.

The core principle behind the impedance method for damage detection is that damage to a structure is reflected in a change in the admittance response from a baseline healthy response to an altered, damaged response. This method is generally considered sensitive to small-sized damage because the admittance information is extracted in the high frequency range $(5+\mathrm{KHz})$. In addition, admittance changes are generally most significant around the structures resonant peaks, because damage often causes a shift in resonant frequencies, and the response amplitudes are the highest around resonant frequencies [9]. A high level of sensitivity can therefore be achieved by monitoring the admittance response around the structure's high frequency resonant peaks. Because of this sensitivity level, the impedance-based method has the potential to detect both the magnitude and location of damage on a structure by how the admittance response changes from the baseline response. Previous studies in controlled lab settings have shown the 
feasibility of impedance-based damage detection with piezoelectric transducers bonded to various structures $[8,10,12]$. In addition, impedance-based technique using Macro Fiber Composite (MFC) has been tested in a lab setting on a .14m long railroad section [13].

\subsection{Inductive Circuitry Enhancements}

The standard impedance approach has a significant shortcoming however. When used in the high frequency range to detect small-sized damage, the impedance approach suffers from a low signal-to-noise ratio. This makes discerning the difference between damage and other factors, such as noise and environmental effects, difficult at times. To improve the low signal-tonoise ratio, a new impedance approach is proposed that combines the standard impedance approach with piezoelectric circuitry, specifically a tunable inductor connected in series with the resistor and the transducer. This modifies the traditional $\mathrm{RC}$ series circuit of a resistor and the transducer into an RLC series circuit. In system dynamics, circuitry elements such as inductors, resistors, and capacitors are systematically equivalent to the mass, damping, and stiffness elements in a mechanical structure, respectively. Therefore, the integration of inductive circuitry, in theory, should alter the energy distribution and affect the dynamic response of the system [9].

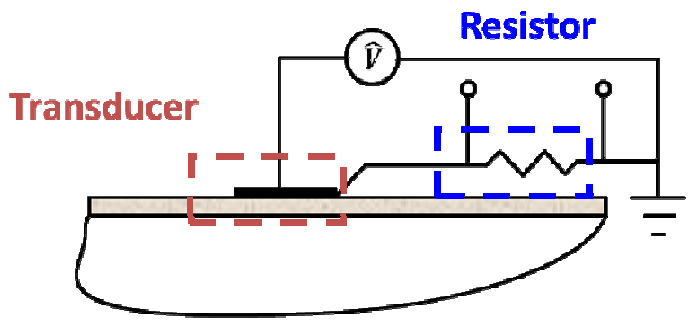

Figure 2A. Current RC Method

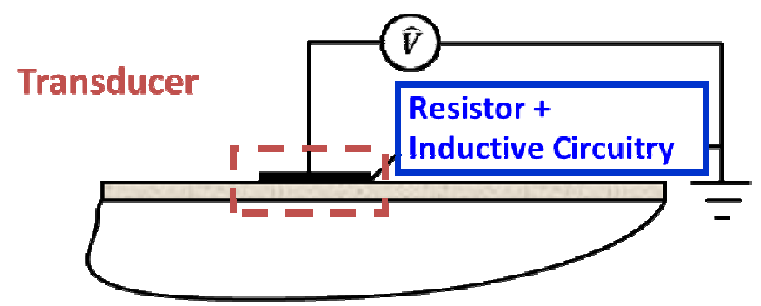

Figure 2B. Proposed RLC Method 
For the case where the piezoelectric patch is connected in series with the resistor, inductor (L), and voltage source, the voltage across the piezo is related to the input voltage by the following relationship:

$$
\mathrm{V}_{\mathrm{a}}=-\mathrm{L} \ddot{\mathrm{Q}}-\mathrm{R} \dot{\mathrm{Q}}+\mathrm{V}_{\mathrm{i}}
$$

which, when substituted into the original equations of motion, results in the new equations of motion:

$$
\begin{aligned}
& \mathrm{m} \ddot{\mathrm{q}}+\mathrm{g} \dot{\mathrm{q}}+\mathrm{kq}+\mathrm{k}_{1} \mathrm{Q}=\mathrm{F}_{\mathrm{m}} \\
& \mathrm{L} \ddot{\mathrm{Q}}+\mathrm{R} \dot{\mathrm{Q}}+\mathrm{k}_{2} \mathrm{Q}+\mathrm{k}_{1} \mathrm{q}=\mathrm{V}_{\mathrm{i}}
\end{aligned}
$$

Here, $\mathrm{R}$ is the total circuit resistance, which is a summation of the tunable inductor resistance $\left(\mathrm{R}_{\mathrm{L}}\right)$ and the additional resistor in the circuit $\left(\mathrm{R}_{\mathrm{S}}\right)$. Under harmonic excitation, the two new equations of motion are transferred to the frequency domain. The resulting transfer functions between structural response and external disturbance and between structural response and input voltage are, respectively:

$$
\begin{aligned}
& \frac{\bar{q}}{\overline{\mathrm{F}}_{\mathrm{m}}}=\frac{-\mathrm{L} w^{2}+\mathrm{Riw}+\mathrm{k}_{2}}{\left(-\mathrm{Lw}^{2}+\mathrm{Riw}+\mathrm{k}_{2}\right)\left(-\mathrm{m} \mathrm{w}^{2}+\mathrm{igw}+\mathrm{k}\right)-\mathrm{k}_{1}^{2}} \\
& \frac{\overline{\mathrm{q}}}{\overline{\mathrm{V}}_{\mathrm{i}}}=\frac{\mathrm{k}_{1}}{\mathrm{k}_{1}^{2}-\left(-\mathrm{Lw}^{2} \mathrm{Riw}+\mathrm{k}_{2}\right)\left(-\mathrm{m} \mathrm{w}^{2}+\mathrm{igw}+\mathrm{k}\right)}
\end{aligned}
$$

and the output voltage measured across the resistor is given as:

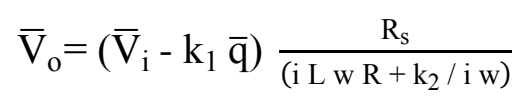

Combining equations (16b) and (16c) results in the electrical admittance of piezoelectric circuitry:

$$
\widehat{Y}_{L}=i w \frac{-m w^{2}+i c w+k}{\left(-L w^{2}+i R w+k_{2}\right)\left(-m w^{2}+i c w+k\right)-k_{1}^{2}}
$$

and the resulting normalized admittance is: 


$$
\frac{\widehat{Y}_{L}}{\widehat{Y}_{p}}=\frac{k_{2}\left(-m w^{2}+i c w+k\right)}{\left(-L w^{2}+i R w+k_{2}\right)\left(-m w^{2}+i c w+k\right)-k_{1}^{2}}
$$

It can be seen that inductive circuitry introduces an additional degree of freedom (DOF) to the system, which creates an additional resonant effect in the admittance response. Indeed, Wang and Tang [9] utilized inductive circuitry in an impedance-based approach to detect smallsized damage on an isotropic, homogenous, and linearly elastic narrow-strip beam with clampedclamped boundary conditions. Upon integrating a tuned inductor to the circuit with piezoelectric transducer attached to the beam, the results showed that inductive circuitry increased the current through the circuit and amplified the signal-to-noise ratio. In addition, the results emphasized the importance of properly tuning the inductor. The integration of an inductor into the circuit creates an electrical resonant effect that, when properly tuned close to one of the structure's resonant peaks, has the ability to significantly amplify the damage-induced admittance change. The optimal inductance value (L) for the RLC circuit at each mode is initially determined from the equation below:

$$
\mathrm{L}=\frac{1}{4 \square^{2} \overline{\mathrm{C}}_{\mathrm{p}}\left(\mathrm{f}_{\mathrm{o}}\right)^{2}}
$$

where $f_{o}$ is the natural frequency in Hz. From this initial value, the final value is obtained from fine inductance tuning [9]. A detailed formulation of the fine inductance tuning process is found in section 8.2 in the Appendix.

The integration of inductive circuitry in the impedance-based approach has several potential benefits for railway health monitoring. The amplification caused by inductive circuitry will in theory increase total sensitivity and allows the operator to more clearly detect small sized damage on the rail track. With a tunable inductor, the operator would have the ability to tune to any of the rail's natural frequencies and inspect the rail under various modes. As will be shown 
in the following sections, damage materializes itself differently for each mode, and the ability to excite and amplify a multitude of modes is of great importance. In addition, increasing sensitivity will consequently reduce cost, as fewer sensors would have to be bonded to the rail to detect the presence of damage.

\section{PRELIMINARY STEPS}

\subsection{Fixed-Fixed Aluminum Strip Beam}

Before carrying out experimental analysis on a full scale railway track, three preliminary investigations in a controlled lab setting are performed to prove the concept of the impedancebased damage detection approach with and without inductive circuitry. The first investigation utilizes a fixed-fixed aluminum strip beam as the host structure, with a length of $60 \mathrm{~cm}$, width $.7 \mathrm{~cm}$, thickness $.3 \mathrm{~cm}$, density of $2,780 \mathrm{~kg} / \mathrm{m}^{3}$, and Young's Modulus of $73.1 \mathrm{e} 9 \mathrm{~N} / \mathrm{m}^{2}$. A piezo transducer from Piezo Systems (http://www.piezo.com/) is bonded to the beam using a thin layer of epoxy adhesive, and leads are soldered to the transducer to connect to the circuit. This setup is similar in nature to the analysis in Wang and Tang [9]. The parameters of the transducer and beam experimental setup are found in Table 1 and Figure 3, respectively:

\section{Table 1. Sensor Parameters}




\begin{tabular}{|l|l|}
\hline Length (cm) & 1.7 \\
\hline Width (cm) & .7 \\
\hline Thickness (cm) & .1 \\
\hline Density (g/cm $\left.{ }^{3}\right)$ & 7800 \\
\hline Young's Midulıs (N/Tr' $\left.{ }^{2}\right)$ & $66 \mathrm{e} 9$ \\
\hline $\begin{array}{l}\text { Piezoelectric Constant } \\
\text { (N/C) }\end{array}$ & $-7.656 \mathrm{e}$ \\
\hline Dielectric Constant (Vm/C) & $6.993 \mathrm{e} 7$ \\
\hline Capacitance (nF) & 1.9 \\
\hline
\end{tabular}

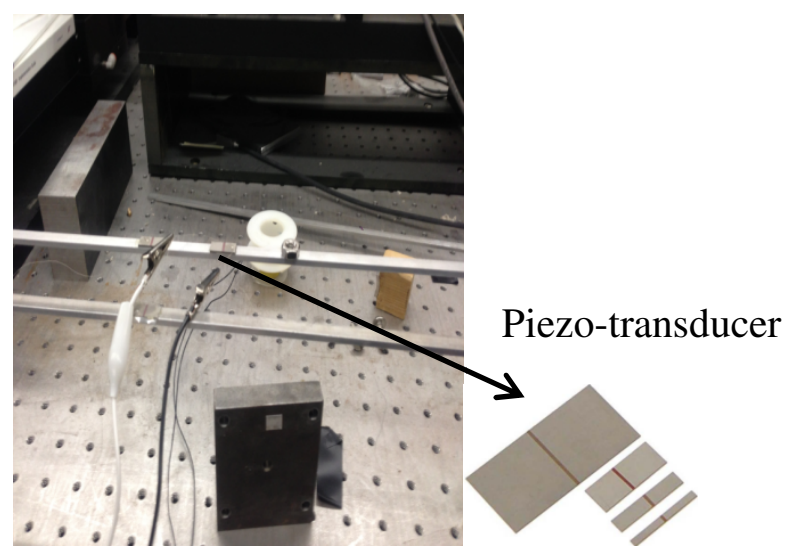

Figure 3. Experimental Setup

For reference, the resistance of the circuit (including the natural resistance of the wires and the capacitor) is $114 \mathrm{ohms}$, and the transducer is located $.32 \mathrm{~m}$ from the left end of the beam. It is worth noting that the proper selection of the resistance value in the circuit is important for a clear admittance response. Too large of a resistance decreases the applied voltage to the PZT and increases circuitry damping which flattens the peak of the admittance response. Too small a resistance decreases the voltage measurement across the resistor, which lowers the signal-tonoise ratio [9].

Because the small strip beam has a traditional fixed-fixed boundary condition, the theoretical, model, and experimental natural frequencies can be easily extracted, leading to better confidence in the experimental results. The $6^{\text {th }}$ mode, or $820.4 \mathrm{~Hz}$ is chosen as the target mode to detect damage. An Agilent 35670A Signal Analyzer (Figure 4) provides the 1V excitation voltage to the PZT and collects the overall admittance response. Channel 1 of the analyzer generates a sinusoidal voltage signal, and Channel 2 measures the voltage drop across the resistor in the circuit to collect the admittance response in the high frequency range. 


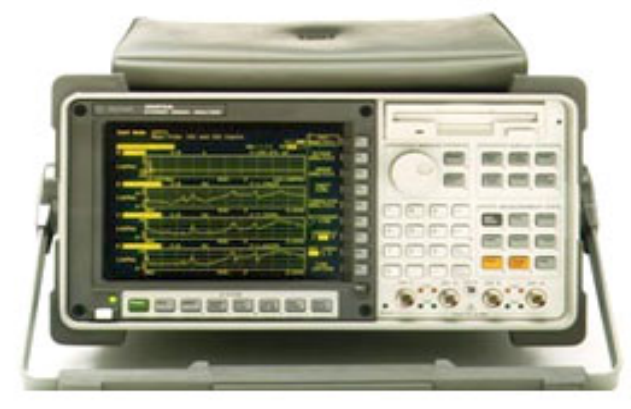

Figure 4. Agilent 5670A Signal Analyzer

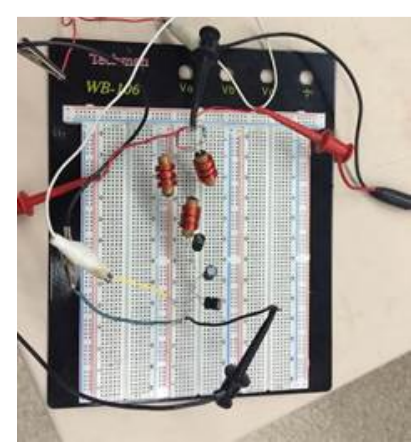

Figure 5. RLC Breadboard Circuit

To represent damage to the strip beam, a second piezo transducer, with length $.017 \mathrm{~m}$, width $.007 \mathrm{~m}$, an height $.003 \mathrm{~m}$, is taped on the top of the beam $.1 \mathrm{~m}$ from the left end. With this setup, both a numerical and experimental analysis is carried out.

\section{a) Numerical Analysis}

To simulate the effects of damage both with and without inductive circuitry on the fixedfixed beam, and to get a general picture of the beam's natural frequencies, a comprehensive MatLab program is developed using the equations previously discussed. The user enters the desired operating mode, whether or not damage is present, and where the damage is along the top of the beam. The program outputs the equivalent modal mass and stiffness, the structural damping, the resonant frequency at the chosen mode, and the optimal inductance value for that resonant frequency. The program also plots various admittance curves depending on the user's needs. It generates a simple RC admittance curve, an RLC curve with the ideal inductance value, and each curve after the beam has been damaged at a certain point. 
For the $6^{\text {th }}$ order, or at $820.4 \mathrm{~Hz}$, the optimal inductance is found to be $20.33 \mathrm{H}$, and the healthy RC and RLC admittance curves, are found in Figures $6 a$ and $6 \mathrm{~b}$, respectively. For reference, in each of the numerical plots, the horizontal axis is frequency in $\mathrm{Hz}$ and the vertical axis is normalized admittance in $\mathrm{db}$.

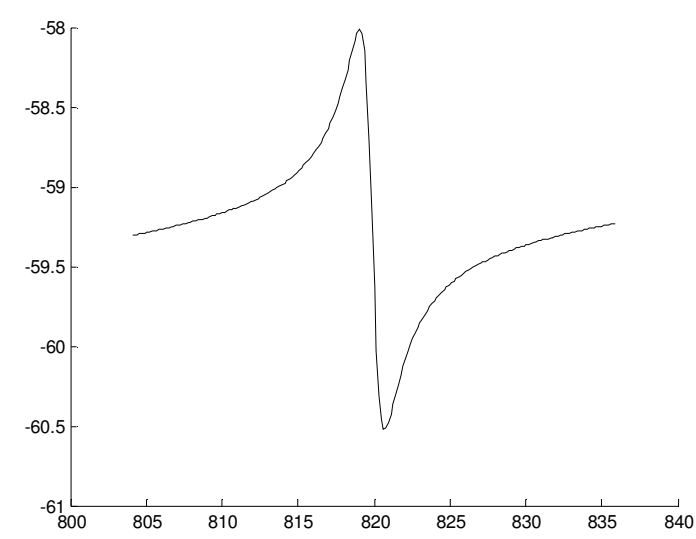

Figure 6a. RC Circuit Admittance

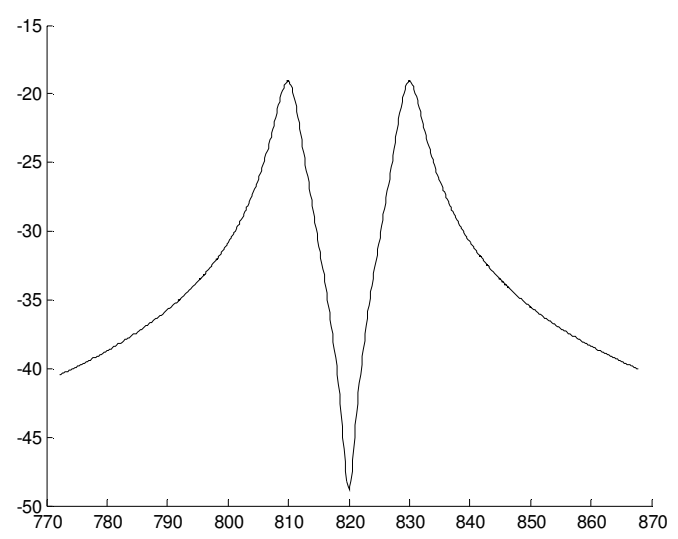

Figure 6b. RLC Circuit Admittance

As theorized, the RC curve has one mechanical resonant peak, while the RLC curve introduces an additional resonant peak in the admittance response. The integration of inductive circuitry greatly increases the magnitude of the admittance curve. The maximum admittance value increases from $-58 \mathrm{db}$ without the inductor to $-19 \mathrm{db}$ with the inductor. In addition, the magnitude of the admittance change at resonance increases from $2.5 \mathrm{db}$ to $28 \mathrm{db}$. This indicates that the integration of inductive circuitry magnifies the sensitivity in the admittance curve around resonance, right where the structure will be monitored for damage.

After damage is added at $.1 \mathrm{~m}$ from the left end, both admittance responses are altered, shown in Figure 7a and 7b, respectively. 


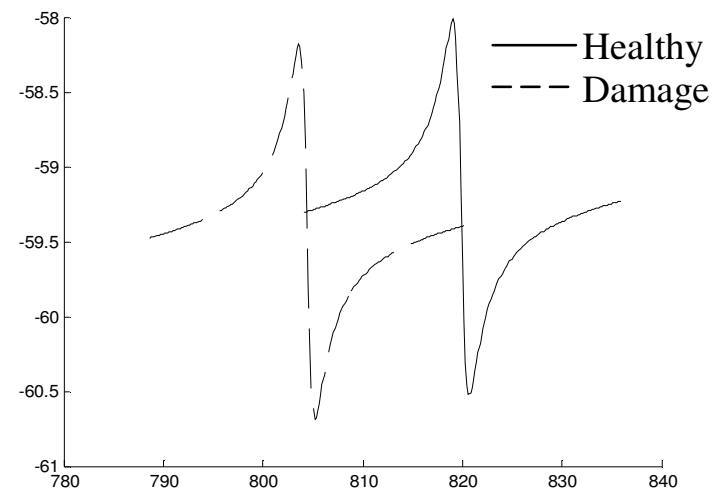

Figure 7a. RC Circuit Damage

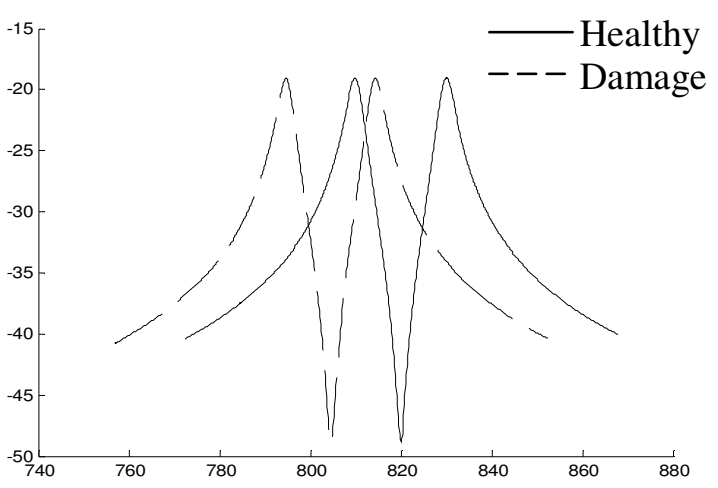

Figure 7b. RLC Circuit Damage

As seen in Figures $7 \mathrm{a}$ and $7 \mathrm{~b}$, the simulated damage causes a shift in the resonant frequency of $14 \mathrm{~Hz}$ to a lower value than the original resonant frequency of the healthy structure. The damage also causes a slight reduction in peak admittance magnitude, although it is not clear if the integration of inductive circuitry magnified the damage-induced admittance change as expected. Although the numerical results seem promising, there is a problem of experimental practicality with the $6^{\text {th }}$ mode, specifically with the integration of inductive circuitry. The $6^{\text {th }}$ mode requires an inductance of $20.33 \mathrm{H}$, which is extremely large and not realistic for a lab experiment. Therefore, the $15^{\text {th }}$ mode or $4,720 \mathrm{~Hz}$, with a corresponding inductance value of $.6223 \mathrm{H}$, was chosen as a second mode to conduct numerical analysis. The $15^{\text {th }}$ mode can be compared with a feasible experimental analysis, and it also provides a comparison to the $6^{\text {th }}$ mode results to verify the numerical findings. The $15^{\text {th }}$ mode healthy RC and RLC admittance responses are shown in Figures 8a and 8b, respectively. 


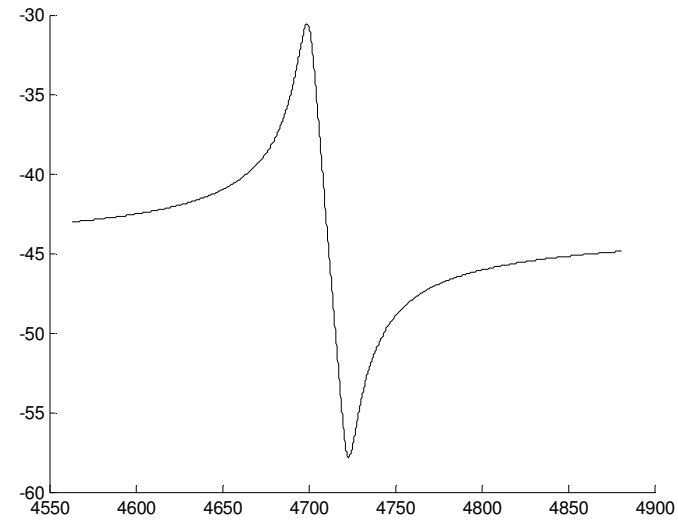

Figure 8a. RC Circuit Admittance

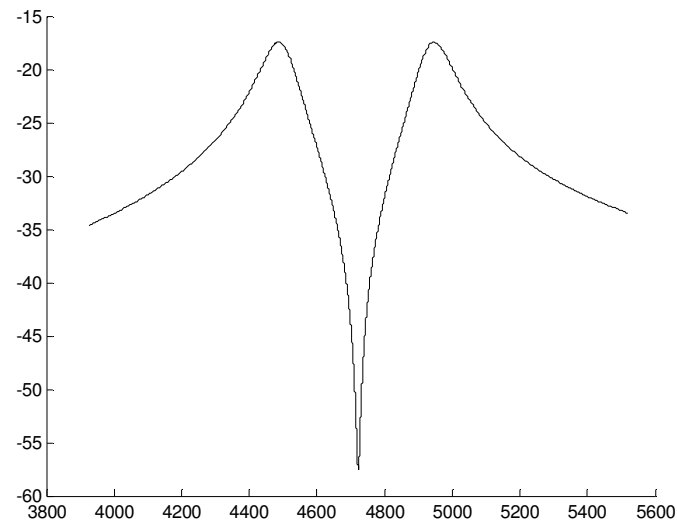

Figure 8b. RLC Circuit Admittance

The results are similar to $6^{\text {th }}$ mode, in that the integration of inductive circuitry magnifies the change in the admittance curve around resonance, except that inductive circuitry does not improve the performance for the $15^{\text {th }}$ mode as much as the $6^{\text {th }}$ mode. Upon applying damage, the results (Figure 9a, 9b) show that the $15^{\text {th }}$ mode is more sensitive to small sized damage than the $6^{\text {th }}$ mode, with a frequency shift of $193 \mathrm{~Hz}$ compared to $14 \mathrm{~Hz}$. It is important to note that the for both $6^{\text {th }}$ and $15^{\text {th }}$ mode RLC damaged responses, the model recalculated the optimal inductance with the damaged condition. Otherwise, the response would be significantly different, as seen in the latter experimental results in subsection (b).

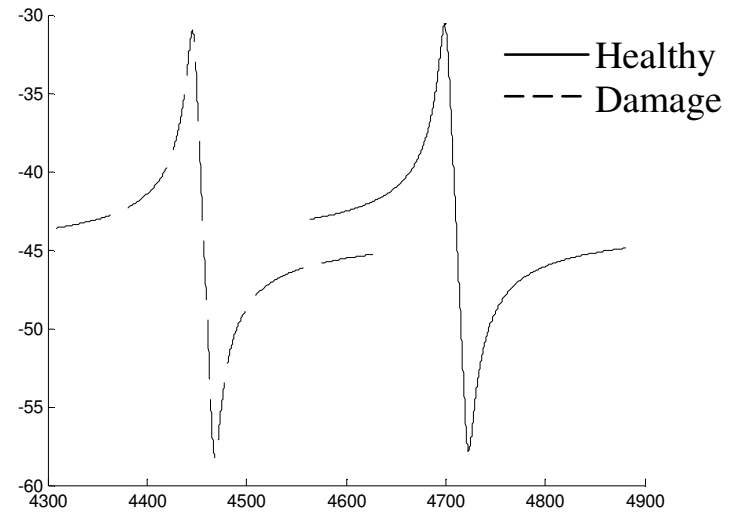

Figure 9a. RC Circuit Damage

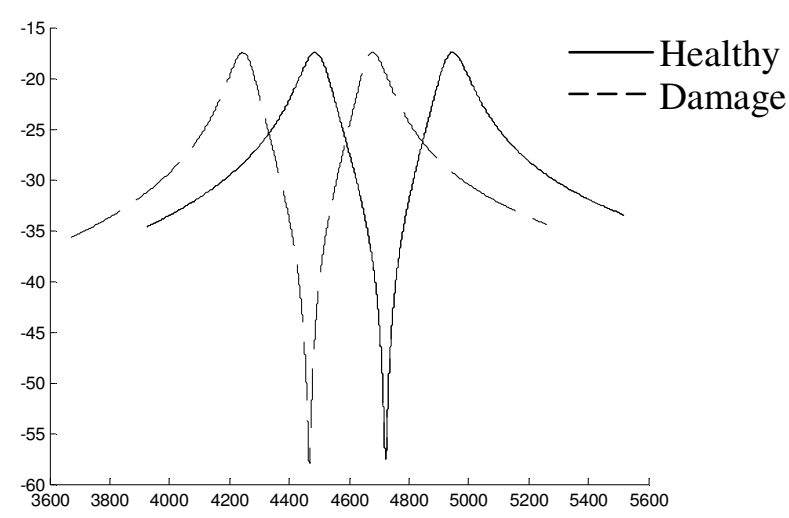

Figure 9b. RLC Circuit Damage 
This result emphasizes a challenge going forward: For a given damaged condition, certain modes appear more sensitive than others to the damage. In the same manner, a given mode may be able to sense certain damaged conditions, but not others. The questions at hand are how does one know which modes to monitor at, and how can one be sure that the admittance change at a mode is indeed damage, when damage at one mode may drastically change the response but may not change the response as much for another mode. These challenges will be further discussed in the following investigations.

\section{b) Experimental Analysis}

The MatLab model for numerical analysis clearly demonstrates the effects of inductive circuitry and damage on the admittance response of the system. However, the numerical results are ideal cases, and in reality it is challenging to see the level of performance that the model predicts. This is mostly because the overall impedance of the transducer is difficult to quantify. Specifically, the inherent resistance of the piezoelectric sensor is frequency dependent, causing much larger resistances and impedance values for the transducer than estimated by the model [15]. Nevertheless, if the effects of inductive circuitry and damage can be clearly seen experimentally, and if the results closely resemble the numerical results, the underlying theory will be proven, and the concept is worth extending to further investigations. Each numerical test is repeated experimentally to compare the admittance curves and overall transducer performance.

As mentioned in the numerical results section, there is a need to operate at a much higher beam order, simply because too large of an inductor is required at low frequencies in order to achieve electrical resonance close to the mechanical beam resonance. For higher orders, the 
required inductance drops below $1 \mathrm{H}$, and this requirement can be satisfied in a lab setting. The healthy experimental RC and RLC admittance curves for the beam's $15^{\text {th }}$ mode are shown in Figures 10a and 10b, respectively.

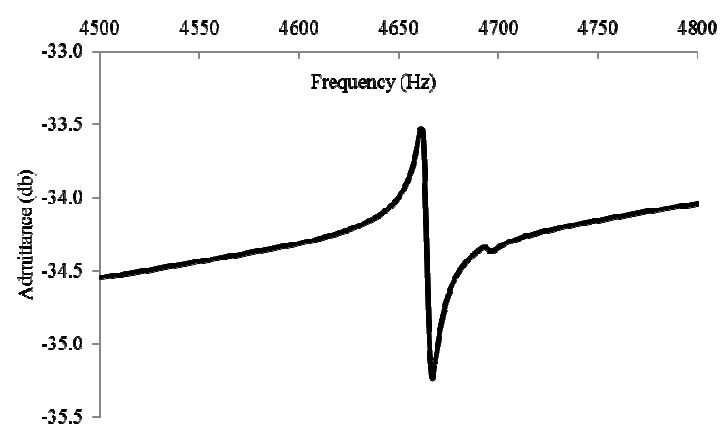

Figure 10a. RC Circuit Admittance

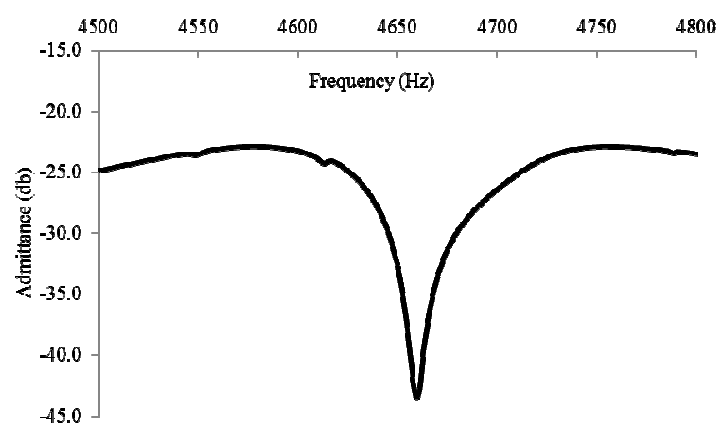

Figure 10b. RLC Circuit Admittance

For reference, a sample of the theoretical, numerical, and experimental natural frequencies for the strip beam can be found in section 8.3 in the Appendix. It confirms the accuracy of both the numerical and experimental frequency results to the theoretical values. The $15^{\text {th }}$ mode resonant frequency is found to be $4,660 \mathrm{~Hz}$ or $60 \mathrm{~Hz}$ lower than the numerical value of $4,720 \mathrm{~Hz}$. For the RLC healthy response, the inductor is tuned to $.6223 \mathrm{H}$ to match the MatLab simulation, and the result is close to optimal because the two resonant peaks are almost equal in magnitude and concavity. Overall, the results are in alignment with the findings in [8] and the previous investigations. Specifically that inductive circuitry introduces an additional resonant peak as opposed to only one resonant peak without inductance, and the integration of inductive circuitry increased both the maximum admittance value and the admittance change at resonance. The addition of the tuned inductor amplified the admittance change of the circuit by $15 \mathrm{db}$ and increase the max admittance value from $-33.5 \mathrm{db}$ to $-21.5 \mathrm{db}$. This means that the maximum 
difference in current measurement for the same voltage excitation increased by four times, which leads to an increase in the signal to noise ratio in measurement.

The experimental results and numerical result align very well. The admittance change for the numerical is $17 \mathrm{db}$, which is very close to the $15 \mathrm{db}$ found experimentally. Again, the model is an ideal case, so the performance will be slightly higher. Both show that inductive circuitry greatly increases admittance change, which is an excellent improvement to the overall sensitivity of the system.

When damage is taped on the top of the beam at .1m from the left end, both admittance curves are drastically affected, as shown in Figures 11a and 11b, respectively.

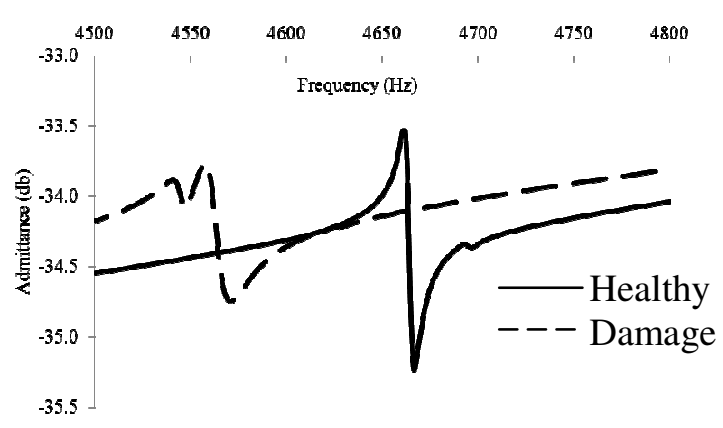

Figure 11a. RC Circuit Damage

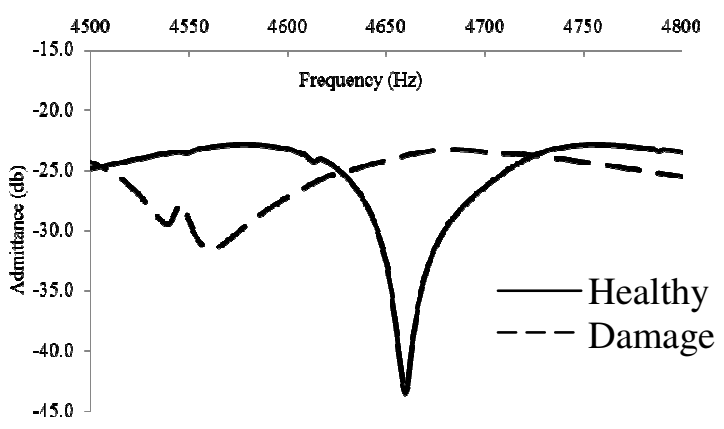

Figure 11b. RLC Circuit Damage

For both cases, damage is shown in the $100 \mathrm{~Hz}$ frequency shift and in a significant

amplitude change of the admittance response. This confirms that the transducer can clearly detect the presence of damage on the beam. More noticeably is the damaged inductive circuitry response, which does not at all resemble the healthy response. This particular response is the product of an off-tuned inductor post damage. Since the structural impedance has changed, the inductor is no longer properly tuned for electrical resonance near the new mechanical natural 
frequency. This causes a change of the shape of the curve and a loss of the two clear resonant peaks. In addition, the admittance change greatly decreases, which shows the importance of properly tuning the inductor to achieve optimal performance. For a $100 \mathrm{~Hz}$ shift, the difference in optimal value is approximately $27.6 \mathrm{mH}$, which can completely change the resulting impedance curve. After the $100 \mathrm{~Hz}$ change, the new optimal inductance value is approximately $.6509 \mathrm{H}$. For a slight frequency shift upon the presence of damage, the optimal inductance value change has little impact on performance, but for this small beam case, it has a large impact.

Overall, both the numerical and experimental data show that the transducer can detect the presence of damage on the beam, and that inductive circuitry increases the overall sensitivity of the system. These positive results are carried forward to the following two preliminary investigations, which respectively take into consideration the cross-sectional shape, and the size of a rail section.

\subsection{Railway Segment}

The second investigation considers the cross-section of a railway, addressing challenges such as where the PZT would be attached, and if the PZT would be able to effectively excite the modes of the complex rail shape. This investigation uses a $.3 \mathrm{~m}$ cut segment of $65.5 \mathrm{~kg} / \mathrm{m}$ AREA rail made of 1050 carbon steel laying on a plastic table as the host structure. It has a density of 7.85 $\mathrm{g} / \mathrm{cm} 3$ and an elastic modulus of 206GPa. This rail type is commonly used on United States railways, and is the same rail type used in the following full railway experimental analysis. The cross sectional dimensions of the rail are found in Table 2 with reference to Figure 12: 
Table 2. Rail Dimensions

\begin{tabular}{|c|c|c|c|c|c|c|c|c|c|c|}
\hline $\begin{array}{c}\text { Rail } \\
\text { Type }\end{array}$ & $\begin{array}{c}\mathrm{HT} \\
(\mathrm{cm})\end{array}$ & $\begin{array}{c}\mathrm{BW} \\
(\mathrm{cm})\end{array}$ & $\begin{array}{c}\mathrm{HW} \\
(\mathrm{cm})\end{array}$ & $\begin{array}{c}\mathrm{W} \\
(\mathrm{cm})\end{array}$ & $\begin{array}{c}\mathrm{HD} \\
(\mathrm{cm})\end{array}$ & $\begin{array}{c}\mathrm{FD} \\
(\mathrm{cm})\end{array}$ & $\begin{array}{c}\mathrm{BD} \\
(\mathrm{cm})\end{array}$ & $\begin{array}{c}\mathrm{E} \\
(\mathrm{cm})\end{array}$ & $\begin{array}{c}\text { Cross } \\
\text { Sectional } \\
\text { Area }\left(\mathrm{cm}^{2}\right)\end{array}$ & $\begin{array}{c}\text { Moment } \\
\text { of Inertia } \\
\left(\mathrm{cm}^{4}\right)\end{array}$ \\
\hline $\begin{array}{c}65.5 \\
\mathrm{~kg} / \mathrm{m} \\
\text { AREA }\end{array}$ & 18.09 & 15.24 & 7.62 & 1.67 & 4.44 & 10.64 & 3.02 & 7.86 & 83.55 & $3,671.02$ \\
\hline
\end{tabular}

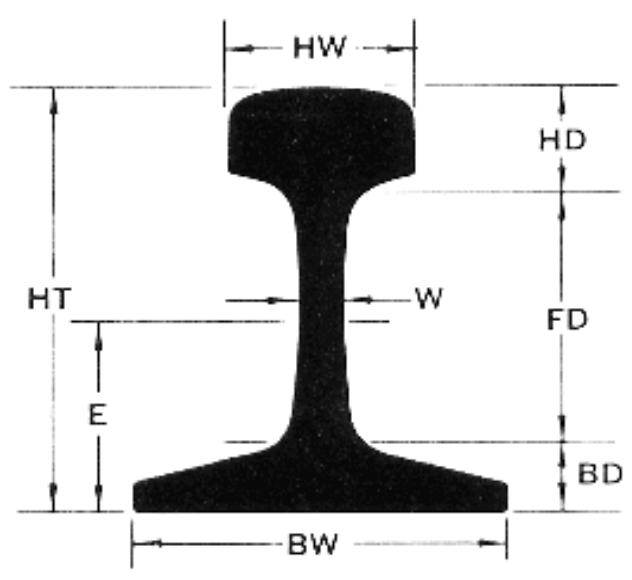

Figure 12. Rail Cross-Section

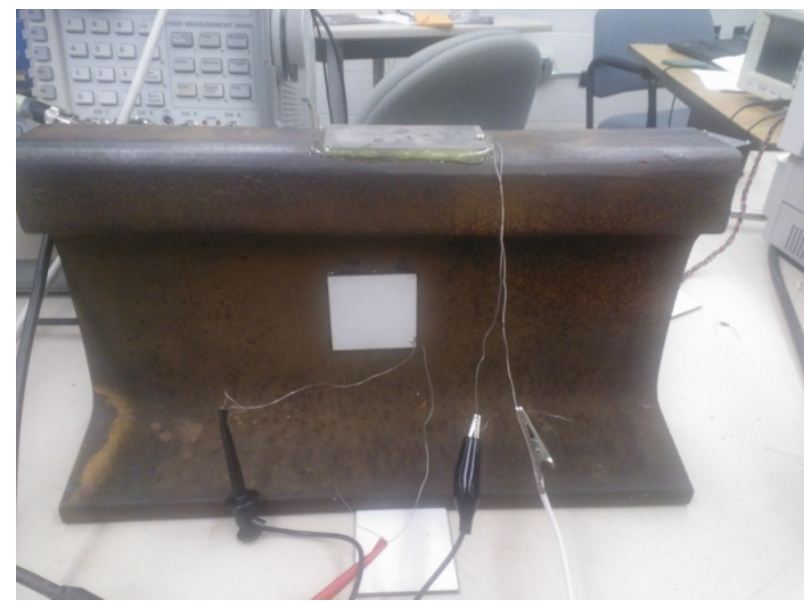

Figure 13. PZT Attached to Rail Segment

The PZT used in this investigation, the following investigation, and the experimental railway analysis is a piezo-ceramic plate manufactured by Steminc Piezo (http://www.steminc.com/), with dimensions and material properties listed in Table 3: 
Table 3. PZT Parameters

\begin{tabular}{|l|l|}
\hline Length $(\mathrm{cm})$ & 4.5 \\
\hline Width $(\mathrm{cm})$ & 4.5 \\
\hline Thickness $(\mathrm{cm})$ & .28 \\
\hline Density $\left(\mathrm{g} / \mathrm{cm}^{3}\right)$ & 7.9 \\
\hline Young's Modulus $(\mathrm{GPa})$ & 73 \\
\hline $\begin{array}{l}\text { Piezoelectric Constant } \\
\left({ }^{*} 10 \mathrm{e}-9 \mathrm{~cm} / \mathrm{V}\right)\end{array}$ & 320 \\
\hline Dielectric Constant $\left(\mathrm{C}_{33} /{ }^{\mathrm{z} 0}\right)$ & 1400 \\
\hline Capacitance $(\mathrm{nF})$ & 6.7 \\
\hline
\end{tabular}

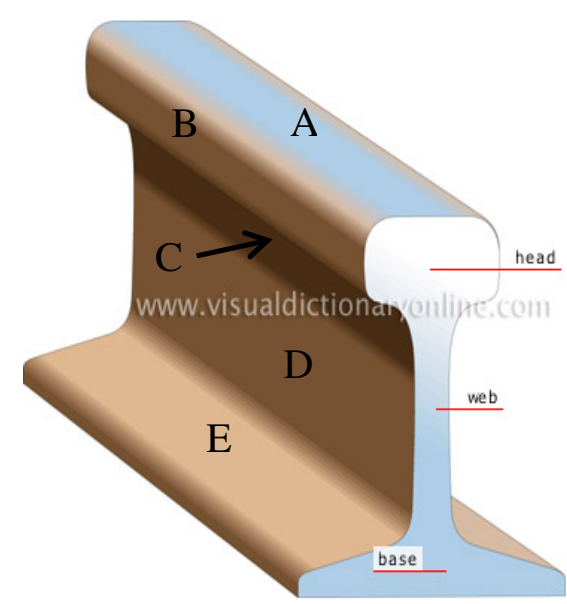

Figure 14 Possible PZT Locations

There are several areas on the track section where the PZT can be attached. The respective sections are labeled A-E on Figure 14. Theoretically, the PZT can be placed on any of these faces, but for practical use, only one face is suitable. The train uses the head of the track (face A). The foot of the track (face E) is often buried under the ground or overlaid with wood supports. The cross-sectional areas of face B and face C (underside) are both small. In addition, face $\mathrm{C}$ is curved, so the PZT does not sit flat on the surface. The suitable location is face D, or the web of the track section. The PZT is bonded to the center of the web, at the middle of the rail section, .15m from the left end (Figure 13).

\section{a) Experimental Analysis}

Upon bonding the PZT to the rail segment, a frequency sweep is performed using the Agilent 35670A signal analyzer, with a 5V input voltage and a total circuit resistance of 99.6 ohms. The resulting natural frequencies can be found in Table 5 in the following finite element analysis section. The resonant frequency of $6.84 \mathrm{KHz}$ was chosen to conduct the experimental analysis, with corresponding optimal inductance of $58 \mathrm{mH}\left(\mathrm{R}_{\mathrm{L}}=159.5 \mathrm{ohms}\right)$. The healthy $\mathrm{RC}$ and RLC admittance curves at this mode are shown in Figures 15a and 15b, respectively: 


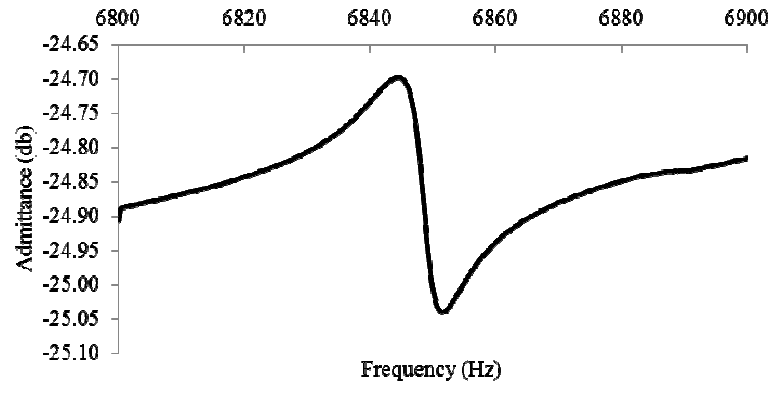

Figure 15a. RC Circuit Admittance

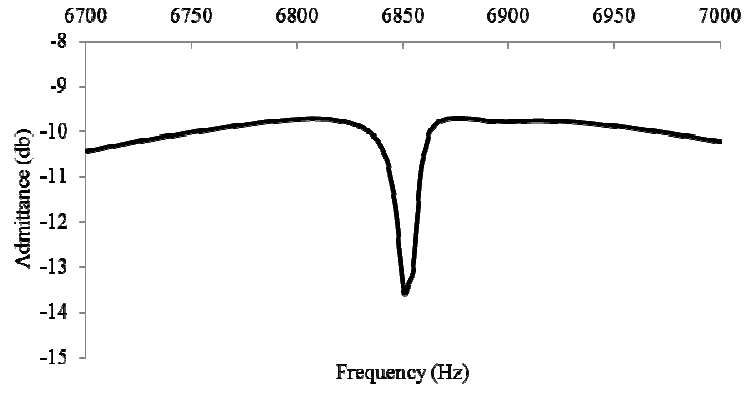

Figure 15b. RLC Circuit Admittance

The integration of inductive circuitry shows similar performance improvements as seen with the aluminum strip beam. The peak admittance magnitude increases from $-27.97 \mathrm{db}$ to -14 $\mathrm{db}$, and the admittance change at resonance significantly increases, from $.3 \mathrm{db}$ to $2.7 \mathrm{db}$. To illustrate the importance of fine tuning the inductor, admittance responses at $57 \mathrm{mH}$ and $59 \mathrm{mH}$ are taken in addition to the optimal $58 \mathrm{mH}$ (Figures 16(a)-(c)).

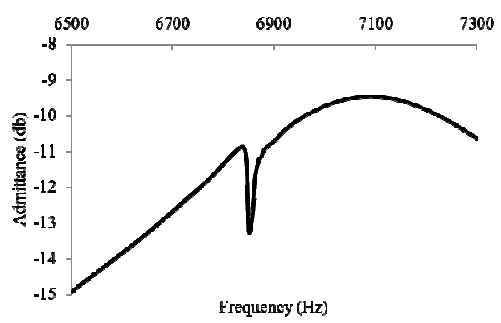

(a). $57 \mathrm{mH}$

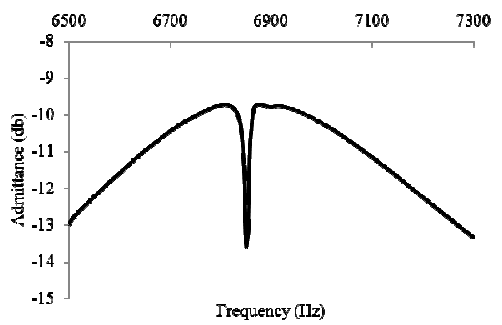

(b). 58mH

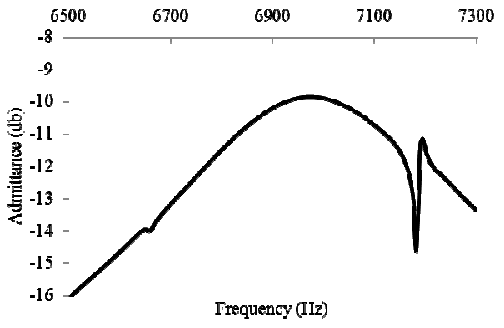

(c) $59 \mathrm{mH}$

Figure 16. Inductor Tuning Effect

When the inductance is set to $57 \mathrm{mH}$, the right peak is significantly higher than the left, and vice-versa for $59 \mathrm{mH}$. This result agrees with the findings in [9]. It is important to note that for both the $57 \mathrm{mH}$ case and $59 \mathrm{mH}$ case, the admittance change at resonance is significantly less than at the optimal $58 \mathrm{mH}$, which illustrates the importance of accuracy in fine tuning the circuit inductance. 
Damage to the rail segment was emulated by placing a second PZT of the same dimensions on the top of the rail segment at $5 \mathrm{~cm}$ from the left end. The RC and RLC results are shown in Figures 17a and 17b, respectively.

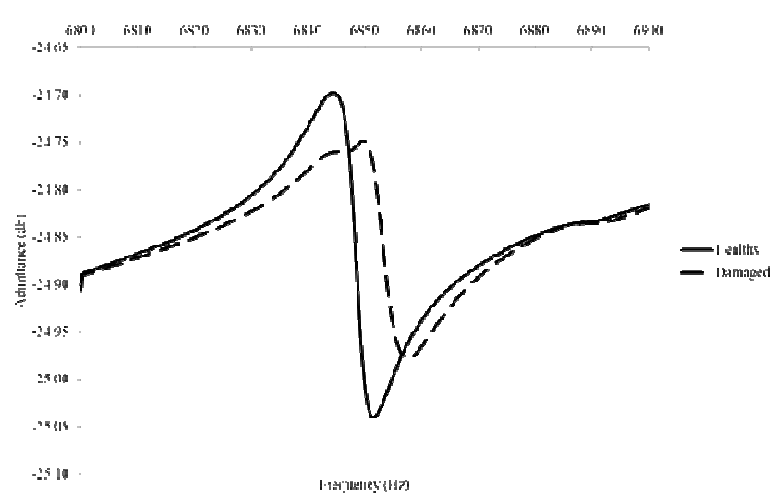

Figure 17a. RC Circuit Damage

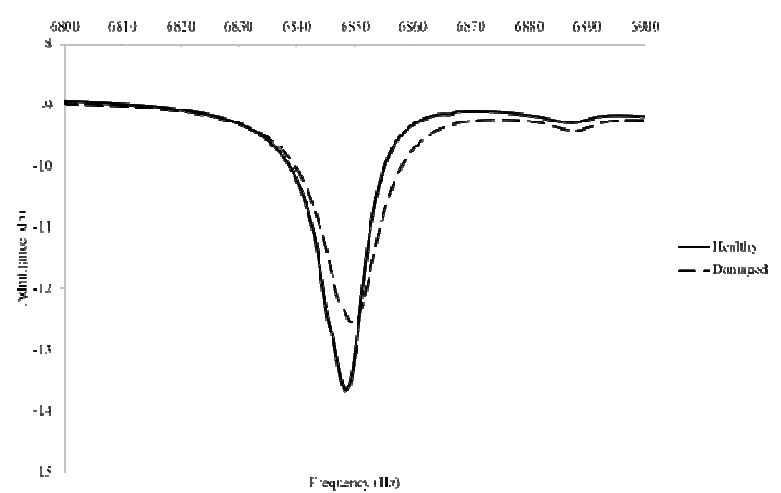

Figure 17b. RLC Circuit Damage

Once again, the PZT is able to detect the presence of damage, this time on the rail segment. The important finding is that the integration of inductive circuitry amplified damage detection sensitivity. Upon applying damage, the RC curve experienced a $5 \mathrm{~Hz}$ frequency shift and a $.1 \mathrm{db}$ decrease in admittance change amplitude. In contrast, the RLC curve experienced a $4 \mathrm{~Hz}$ frequency shift and a $1.2 \mathrm{db}$ decrease in admittance change amplitude. Although the frequency shift is similar, the greater amplitude change from the RLC circuit implies a higher level of sensitivity to small-sized damage. With the RLC circuit, the sensor has the ability to detect damage of lesser magnitude that would not appear when utilizing a simple RC admittance curve.

The results of both inductive circuitry and damage are repeatable for any of the rail section's modes. Below are two other experimental trials, at $4.72 \mathrm{KHz}$ (Figures 18a, 18b) and 9.59KHz (Figures 19a, 19b), respectively. 


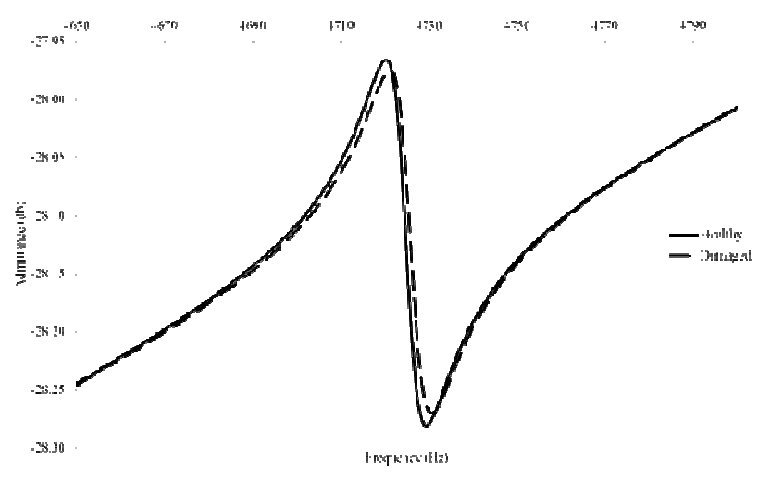

Figure 18a. RC Circuit Damage

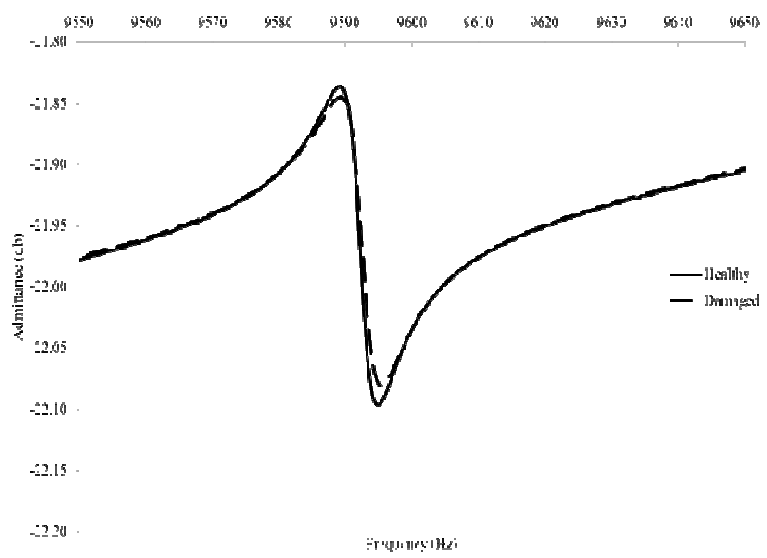

Figure 19a. RC Circuit Damage

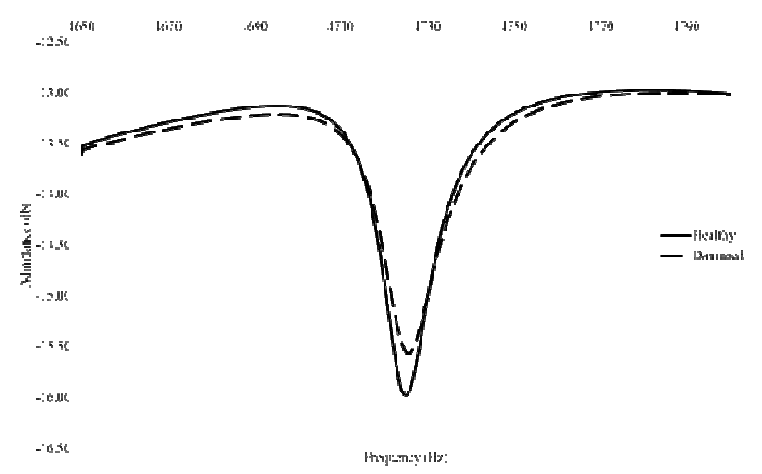

Figure 18b. RLC Circuit Damage

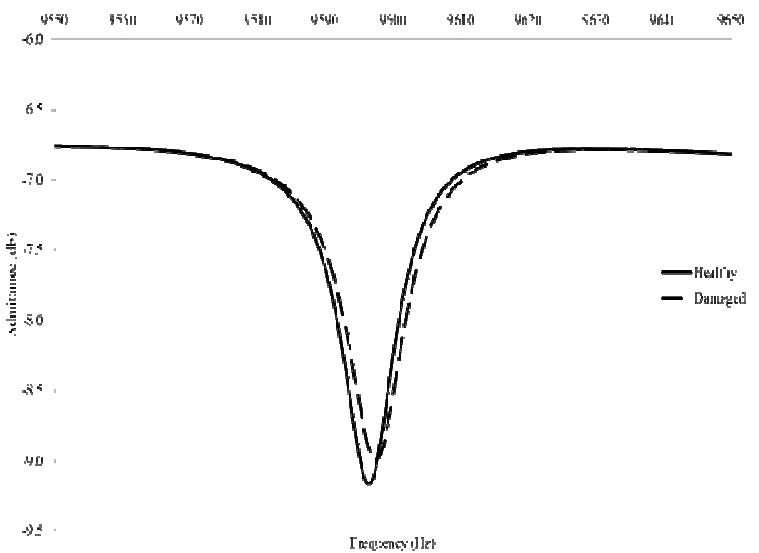

Figure 19b. RLC Circuit Damage

Each trial illustrates an inductive circuitry performance improvement, although the level of improvement varies by mode. Similarly with damage, each trial shows the presence of damage, but the total change in the curve is modal dependent, meaning some modes are more sensitive than other modes to damage being placed on the top of the rail head. This validates the similar numerical finding in the previous investigation. The reasoning behind this will be further explored in the following finite element analysis section. 


\section{b) Finite Element Analysis}

To numerically compare the natural frequencies of the $.3 \mathrm{~m}$ long $65.5 \mathrm{~kg} / \mathrm{m}$ AREA railway track piece to the experimental results, and to gather insight into the rail segment's mode shapes, a finite element model (FEM) is created in ANSYS. The FEM is a Free Mesh, Block Lanczos model, with a Poisson's Ratio assumed to be .3. For boundary conditions, the model assumes that the motion of the base of the rail in the z-axis is constrained. It is important to note that because of computational limits, this FEM could not be used to compare to the following railway experimental analysis, because the rail section is several meters long and would require too many elements to evaluate properly. In addition, as detailed in section 4.1, the boundary conditions of the full railway are complex, which makes mimicking the conditions in an FEM simulation near impossible. For the rail piece in a lab setting however, a reasonable model can be constructed to aid in analysis.

Four rail segment models are created, all with different amounts of elements (resulting in different degrees of freedom). Each segment is run through a modal analysis to find the natural frequencies and mode shapes. The goal is to determine a sufficient amount of elements so that increasing the number of elements beyond that amount does not alter any natural frequency (less the rigid body motions) by more than $0.1 \%$. The four trials, their number of elements, and their max and average percent natural frequency differences from the previous trial, respectively, are found in Table 4. For reference, a complete list of the natural frequencies for each trial can be found in section 8.4 in the Appendix. 
Table 4 Finite Element Accuracy Comparison

\begin{tabular}{|c|c|c|c|}
\hline Trial & $\begin{array}{l}\text { Number of } \\
\text { Elements }\end{array}$ & $\begin{array}{l}\text { Max Percent } \\
\text { Difference }\end{array}$ & $\begin{array}{l}\text { Average Percent } \\
\text { Difference }\end{array}$ \\
\hline 1 & 34,100 & - & - \\
\hline 2 & 99,500 & $1.38 \%$ & $.40 \%$ \\
\hline 3 & 211,400 & $.45 \%$ & $.18 \%$ \\
\hline 4 & 273,600 & $.09 \%$ & $.04 \%$ \\
\hline
\end{tabular}

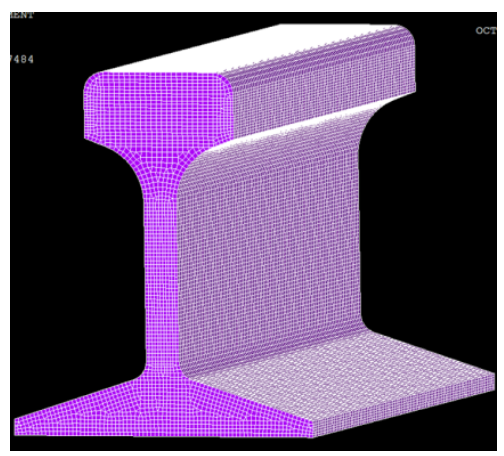

Figure 20 Finite Element Model

It can be seen from Table 4 that neither trial 1 nor trial 2 are sufficiently accurate, but the max percent difference between trial 3 and trial 4 falls within the $0.1 \%$ difference criteria, and the average percent difference is well below that mark. Therefore, the third trial, or 211,400 elements $(\sim 600,000 \mathrm{DOF})$, is sufficiently accurate for the modal analysis, as increasing the number of elements does not alter the resulting natural frequencies. Again, the software has computational limits on the number of elements. A fifth trial was created with over 391,700 elements, but the modal analysis would not compute. If the natural frequencies were still significantly changing as the number of elements approached 400,000, then the model would not have a precise enough accuracy. Fortunately, trial 3 was found to be sufficiently accurate for the modal analysis of this rail segment. A comparison of the numerical natural frequencies from trial 3 to the experimental natural frequencies (less rigid body modes) is found in Table 5. 
Table 5 Natural Frequency Comparison

\begin{tabular}{|c|c|c|c|}
\hline Mode & $\begin{array}{l}\text { Numerical } \\
\text { FEM (Hz) }\end{array}$ & $\begin{array}{c}\text { Experimental } \\
(\mathrm{Hz})\end{array}$ & $\%$ Error \\
\hline 5 & 1115.7 & 1342.2 & $17 \%$ \\
\hline 6 & 2780.9 & 2694.1 & $3 \%$ \\
\hline 7 & 3281.2 & 3001.3 & $9 \%$ \\
\hline 8 & 3360.5 & 4066 & $17 \%$ \\
\hline 9 & 4455.7 & 4350.2 & $2 \%$ \\
\hline 10 & 4782.8 & 4719.7 & $1 \%$ \\
\hline 11 & 4841.5 & 4941.4 & $2 \%$ \\
\hline 12 & 5893 & 5863.6 & $1 \%$ \\
\hline 13 & 6422.6 & 6178.3 & $1 \%$ \\
\hline 14 & 6877.5 & 6843.8 & $0 \%$ \\
\hline 15 & 7166.5 & 8021.8 & $11 \%$ \\
\hline 16 & 8561.6 & 8512.1 & $1 \%$ \\
\hline 17 & 8594 & 8547.6 & $1 \%$ \\
\hline 18 & 8894.7 & 8672 & $3 \%$ \\
\hline 19 & 9049.2 & 9588.1 & $6 \%$ \\
\hline 20 & 9338.3 & 10024 & $7 \%$ \\
\hline 21 & 9455.5 & 10005 & $5 \%$ \\
\hline 22 & 9722.7 & 10162 & $4 \%$ \\
\hline 23 & 10240 & 10255 & $0 \%$ \\
\hline 24 & 10784 & 10409 & $4 \%$ \\
\hline 25 & 12336 & 10865 & $14 \%$ \\
\hline
\end{tabular}

The finite element results match the experimental natural frequencies well up until the higher frequencies (above 9KHz). This confirms the finite element analysis sufficiently approximates the rail segment, including its boundary conditions. A selection of mode shapes from the finite analysis, including the mode shapes that correspond to the previous experimental analysis $(4.72 \mathrm{KHz}, 6.84 \mathrm{KHz}$, and $9.59 \mathrm{KHz})$ are found in Figures $21(\mathrm{a})-(\mathrm{f})$. 


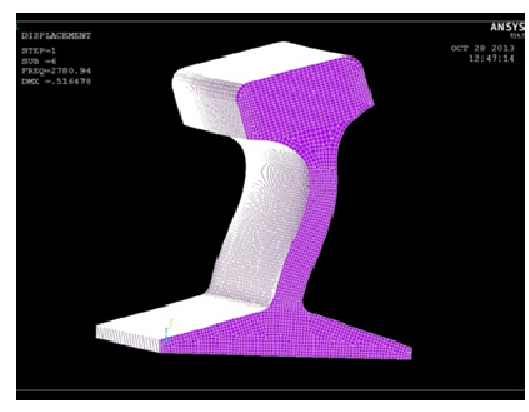

(a) $6^{\text {th }}$ mode

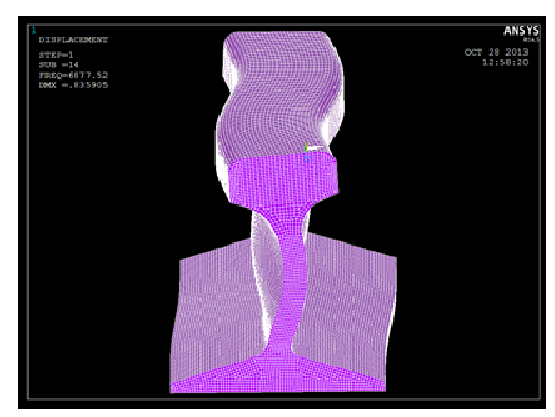

(d) $14^{\text {th }}$ mode

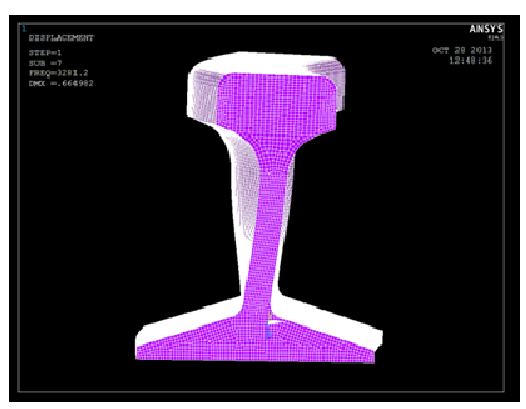

(b) $7^{\text {th }}$ mode

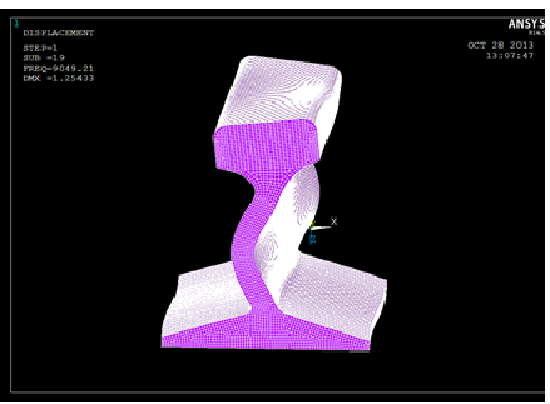

(e) $19^{\text {th }}$ mode

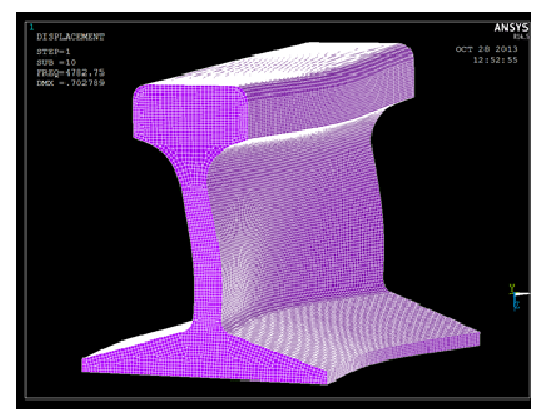

(c) $10^{\text {th }}$ mode

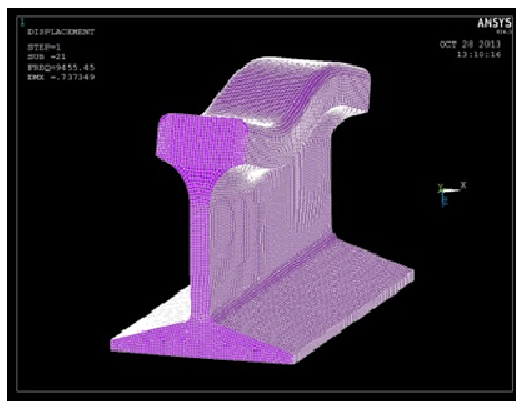

(f) $21^{\text {st }}$ mode

Figure 21(a)-(f) FEM Rail Mode Shapes

As seen in the analysis, as opposed to a thin " $2 \mathrm{D}$ " beam structure, where the mode shapes generally act on the top surface of the beam, for the 3-D rail case (with non-uniform area distribution and complex boundary conditions), the mode shapes materialize in different forms for each mode. Some mode shapes act in the axial direction, some in the transverse direction, some in both axial and transverse, and some in neither.

Because the PZT is on the web of the rail, it can be hypothesized that a mode shape causing large transverse deflection may induce a greater strain in the PZT, thereby creating a higher sensitivity to mechanical impedance changes in the rail (damage detection). This would explain why the $14^{\text {th }}$ mode, experimentally found to be $6.84 \mathrm{KHz}$, was able to more clearly detect the presence of damage than either the $10^{\text {th }}$ mode $(4.72 \mathrm{KHz})$, or the $19^{\text {th }}$ mode $(9.59 \mathrm{KHz})$. As 
seen in the above mode shapes, the $14^{\text {th }}$ mode has the greatest transverse deflection of the three modes, which would result in the greatest strain on the PZT. In order to validate this hypothesis however, a large amount of empirical data would have to be collected, several different damaged conditions would have to be implemented. Nevertheless, the results of the finite element analysis provides insight as to why identical damage conditions materialize themselves differently for each mode, and it emphasizes the importance of having the ability to monitor the railway at several different modes.

For practical implementation purposes however, these challenges are actually not very difficult to solve. A railway operator at any time can instantly excite multiple railway modes to detect the presence of damage. The operator would only need to know the railway's modes, and then each mode could be excited in succession to get a complete picture of the damage. In addition, by gathering a set of healthy responses at each mode, one can establish a distribution of healthy responses, and damage would materialize itself as an outlier. This outlier approach is demonstrated on the railway in sections 6.2 and 6.3 .

\subsection{Stainless Steel Beam}

The third preliminary investigation carried out in a controlled lab setting was on a $2.3 \mathrm{~m}$ long fixed-fixed stainless steel beam, with a width of $4 \mathrm{~cm}$, height $18 \mathrm{~cm}$, a density (p) of 7.7 $\mathrm{g} / \mathrm{cm}^{3}$ and an elastic modulus (E) of $180 \mathrm{GPa}$. The purpose of this setup was to demonstrate the feasibility of the impedance method both with and without inductive circuitry on a scaled structure comparable in size with a full rail segment. This particular setup questions whether or 
not the small PZT can excite a large structure such as the beam or a rail segment. The PZT is bonded on the side of the beam at $115 \mathrm{~cm}$ from the left end and $9 \mathrm{~cm}$ from the top (Figure 22).

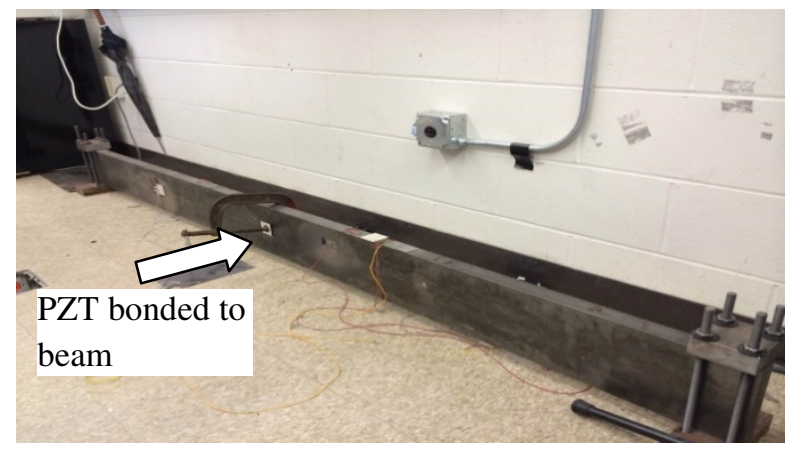

Figure 22 Beam Lab Setup

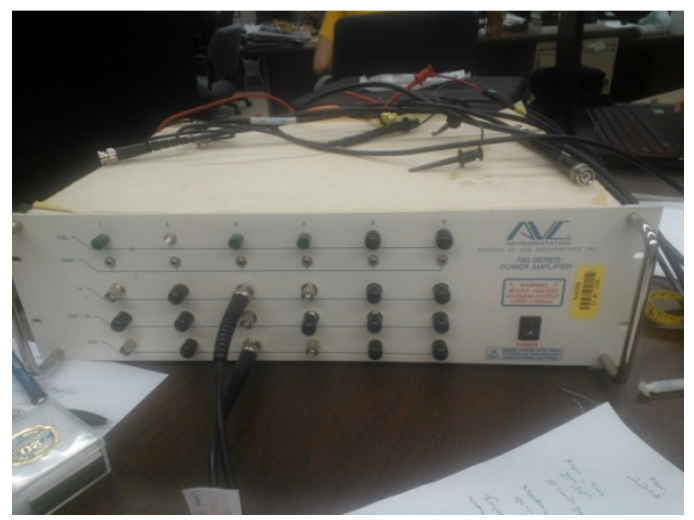

Figure 23 Power Amplifier

Upon commencing the frequency sweep, the input voltage of $5 \mathrm{~V}$ from the signal analyzer proves insufficient in exciting the large stainless steel beam and finding its natural frequencies. A greater input voltage than what the signal analyzer alone could produce is required. To solve this problem, a power amplifier is used to increase the input voltage from the signal analyzer to $10 \mathrm{~V}$. With the amplifier, the input voltage of $10 \mathrm{~V}$ is large enough to excite the beam (Figure 23). Healthy admittance responses are taken at $5,870 \mathrm{~Hz}$, one of the beam's natural frequencies, with and without inductive circuitry. The final inductance value is found to be $94.2 \mathrm{mH}\left(\mathrm{R}_{\mathrm{L}}=255.7\right.$ ohms) for the resonant frequency of $5870 \mathrm{~Hz}$. A damaged response is then taken for each case. Damage is simulated by placing a $4.53 \mathrm{~kg}$ (10lb) block weight on the top face of the beam at 90 $\mathrm{cm}$ to the left of the PZT. Each resulting admittance curve is shown in Figure 24. 

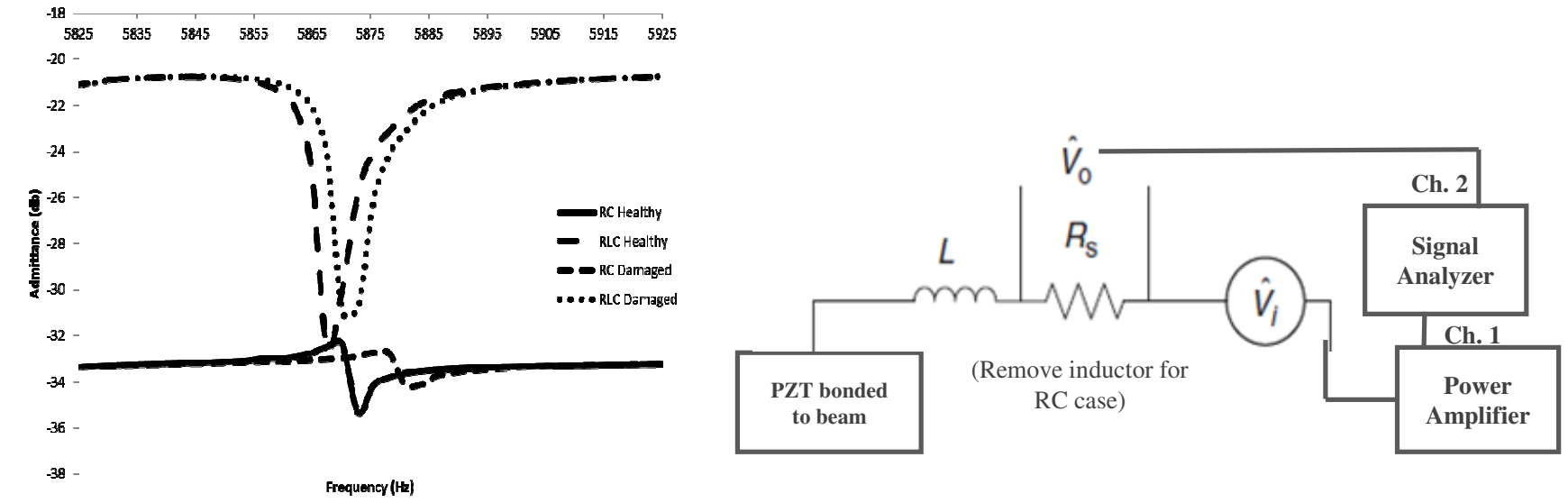

Figure 24. Experimental Admittance Curves

Figure 25. System Configuration

For this particular trial, inductive circuitry increases the maximum admittance value from $-32.38 \mathrm{db}$ to $-20.73 \mathrm{db}$, and the admittance change at resonance increases from $2.8 \mathrm{db}$ to $11.7 \mathrm{db}$, leading to a significant signal-to-noise ratio improvement. For both cases, damage is recognized as a clear change from the healthy response to an altered response, and the resonant frequency shifts $5 \mathrm{~Hz}$. With inductive circuitry however, the peak magnitude change upon damage significantly increased from $.4 \mathrm{db}$ to $1.5 \mathrm{db}$. This shows that the integration of inductive circuitry increases sensitivity and significantly improves overall performance. The successful validation of the impedance-based damage detection method and the integration of inductive circuitry on a $2.3 \mathrm{~m}$ fixed-fixed beam in lab provides the proof-of-concept necessary to extend the approach to a full-scale rail track. 


\section{RAILWAY PROOF OF CONCEPT}

\subsection{Testing Setup}

The following experiments are performed on a $200 \mathrm{~m}$ long, $65.5 \mathrm{~kg} / \mathrm{m}$ AREA rail (identical to the previous investigation) in-use test rail at Sperry Rail Services in Danbury, CT. The specific section of rail used in the experiments is $5.5 \mathrm{~m}$ long. The PZT is bonded at the center of the web, at the middle of the rail section (i.e., $2.75 \mathrm{~m}$ from the left end). It is important to note that PZT capacitance is temperature-dependent. The capacitance of the PZT is measured at $0^{\circ} \mathrm{C}$, and increases $.3 \mathrm{nF}$ as a result of a $10^{\circ} \mathrm{C}$ temperature increase throughout the day. The effect of temperature on the admittance measurement will be further discussed in the analysis section.

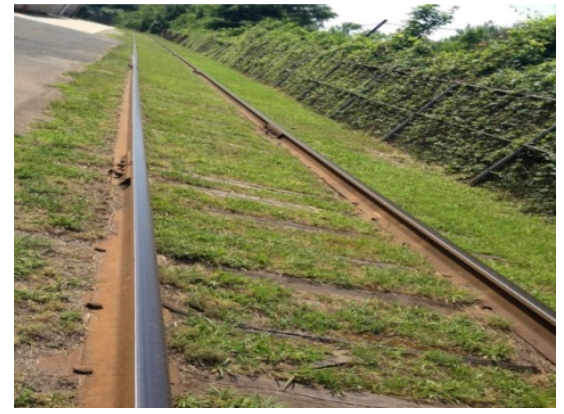

(a). Test Rail at Sperry Rail Services

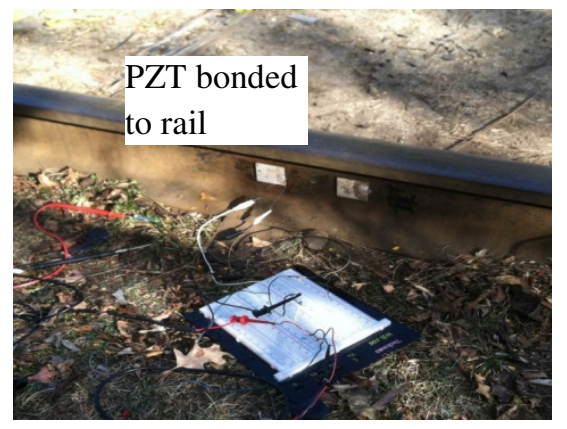

(c). PZT Bonded to Rail Section

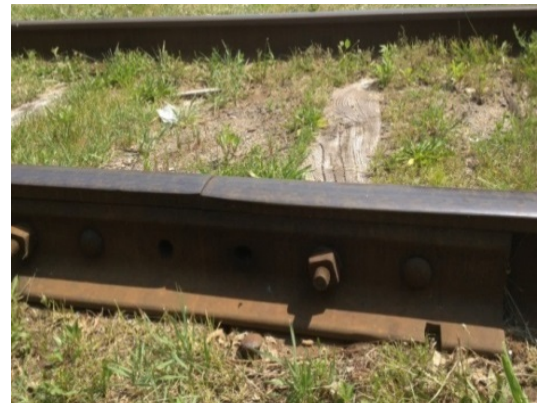

(b). Rail Section Joint

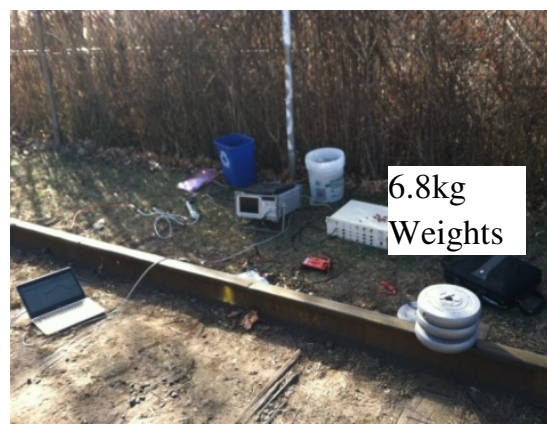

(d). Damage Placed on Rail Section

Figures 26(a)-(d). Experimental Setup on Test Rail 
Structural damage to the head of the rail section is emulated with a number of $6.8 \mathrm{~kg}$ (15lb) circular weights. The weights are placed on Face A of the rail, or the top of the head (Figure 26(d)). With a $50 \mathrm{ohm}$ resistor connected in series with the transducer, a wide range admittance response is taken to locate the rail section's natural frequencies and establish a baseline healthy response. The following experiments are performed using a rail natural frequency of $9,641 \mathrm{~Hz}$, a rail mode which is found to be sensitive to small-sized damage, down to $6.8 \mathrm{~kg}$.

First, a baseline healthy response is taken for the simple RC circuit case. Damaged responses are then taken at a set location of $1 \mathrm{~m}$ from the left side of the PZT by varying the damage magnitude (mass) from $6.8 \mathrm{~kg}$ to $27.2 \mathrm{~kg}$ (Case 1 ). For reference, $6.8 \mathrm{~kg}$ represents a $2 \%$ mass change in the rail section, or a $1.9 \%$ stiffness change. Next, a set of damaged responses are taken by setting a constant weight of $27.2 \mathrm{~kg}$ and varying the location of the damage along the rail, from $1 \mathrm{~m}$ to $2.5 \mathrm{~m}$ from the right side of the sensor, then $4 \mathrm{~m}$ from the sensor, crossing the joint into the next rail section (Case 2). In order to establish a threshold value for an outlier analysis, a second healthy admittance response is taken after all of the damaged cases. The second healthy response accounts for temperature and environmental changes on the rail and the slight change in piezoelectric capacitance throughout the day. The identical procedure is used for the RLC circuit to directly compare performance results. The optimal inductance value (L) for the RLC circuit is found to be $.0382 \mathrm{H}\left(\mathrm{R}_{\mathrm{L}}=102.6 \mathrm{ohms}\right)$ for the resonant frequency of $9,641 \mathrm{~Hz}$. 


\subsection{Normalized Relative Difference Outlier Analysis}

When using the proposed damage detection approach, damage is shown by a change in the admittance response from the baseline healthy response to an altered, damaged response. In a statistical sense, the damaged response is an outlier to a series of normally distributed healthy responses. It is important to note that any two healthy responses are rarely identical. External factors, such as temperature, weather, environmental noise, and bonding degradation between the PZT and host structure [12], all affect a healthy response. For example, if a healthy measurement is taken in the morning, and a second measurement is taken in the middle of the day when the temperature has risen, the second response will have slightly deviated from the first. This is because the capacitance of the PZT is temperature dependent. To account for a distribution in responses, a variety of outlier methods are used in SHM, including root mean squared deviation (RMSD) and other metrics $[13,15]$. In this research, to quantify the change between any two admittance curves, a damage index called the "normalized relative difference" (NRD) is used [17]:

$$
\mathrm{NRD}=\int_{\mathrm{w}_{1}}^{\mathrm{w}_{2}} \frac{\left|\hat{\mathrm{x}}_{\text {monitored }}-\hat{\mathrm{x}}_{\text {baseline }}\right| \mathrm{dw}}{\mathrm{w}_{2}-\mathrm{w}_{1}}
$$

In a way, the NRD is the normalized ratio of the absolute difference between a baseline measurement and the monitored measurement. The NRD is taken within a set frequency range, where $\mathrm{w}_{1}$ is the lower frequency bound and $\mathrm{w}_{2}$ is the upper frequency bound. 


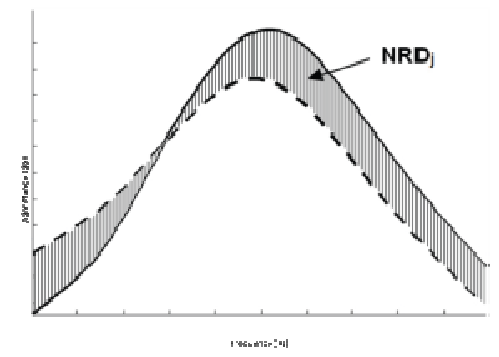

Figure 27. Normalized Relative Difference Illustration [16]

The solid line in Figure 27 is a baseline admittance measurement, and the dashed line is the monitored measurement. The quantity is the shaded area between and , which represents the total difference between the two curves [17]. An NRD value is a non-dimensional indicator of this total difference between two curves. Therefore, the distribution of healthy responses creates a "threshold" NRD value, where any NRD value below the threshold is considered a healthy impedance response, and any NRD value above the threshold is considered an outlier, or damaged response. The NRD outlier analysis can be directly applied to railway damage detection by setting the lower and upper frequency bounds around one of the rail's natural frequencies where the admittance response is taken. Structural damage causes an increased change in vibration pattern within the rail. Therefore, damage on the rail should result in a higher NRD value than environmental effects between any two healthy impedance measurements.

The NRD outlier analysis is particularly useful for railway health monitoring because it takes into account the total difference between two impedance curves, regardless of the mode of operation. This solves the problem of damage materializing itself differently for each mode. Because damage materializes itself as a frequency change for some modes, an amplitude change for other modes, and both for other modes still, statistical methods that only compare frequency 
or amplitude changes are not useful. The NRD method however, can effectively compare a damaged condition to its matching healthy impedance response at any mode.

\subsection{Experimental Analysis}

Upon bonding the PZT to the rail section, experimental analysis is carried out by first taking healthy admittance responses. Figures $28 \mathrm{a}$ and $28 \mathrm{~b}$ show baseline healthy admittance curves taken around $9,641 \mathrm{~Hz}$ without (RC) and with (RLC) inductive circuitry, respectively. As predicted, inductive circuitry introduces an additional resonant peak in the admittance response. The tuning of the inductor to $38.3 \mathrm{mH}$ is near optimal because the two resonant peaks are almost equal in magnitude. Figure $28 \mathrm{~b}$ shows that the integration of inductive circuitry greatly increases the magnitude of the admittance curves. The maximum admittance value increases from $.65 \mathrm{db}$ without the inductor to $15.84 \mathrm{db}$ with the inductor. In other words, for the same voltage input, the maximum difference in current measurement increases by six times, which significantly increases the signal-to-noise ratio. In addition, the magnitude of the admittance change at resonance increases from $.09 \mathrm{db}$ to $.85 \mathrm{db}$. This indicates that the integration of inductive circuitry magnifies the change in the admittance curve around resonance.

Damaged responses are taken at $1 \mathrm{~m}$ from the left side of the PZT by varying the damage magnitude from $6.8 \mathrm{~kg}$ to $27.2 \mathrm{~kg}$, first for the $\mathrm{RC}$ case. The damaged results, as well as the second healthy response (Healthy 2), are shown in Figure 29. Clearly, the PZT has the ability to detect structural changes in the rail from the weights. For this particular sensitive mode, the PZT has the ability to detect damage down to $6.8 \mathrm{~kg}$ of mass. The two healthy admittance 
responses slightly differ. This slight difference is caused by temperature and environmental effects on the railway throughout the course of the day. The Normalized Relative Difference in these two measurements establishes a threshold value for healthy responses. The NRD values for the second healthy response, as well as each damage response, are found in Table 6. NRD values for each response are shown within a larger frequency range $(9610-9680 \mathrm{~Hz})$ and a smaller frequency range closer to resonance $(9630-9660 \mathrm{~Hz})$ in order to give a complete picture of the total difference of each response.

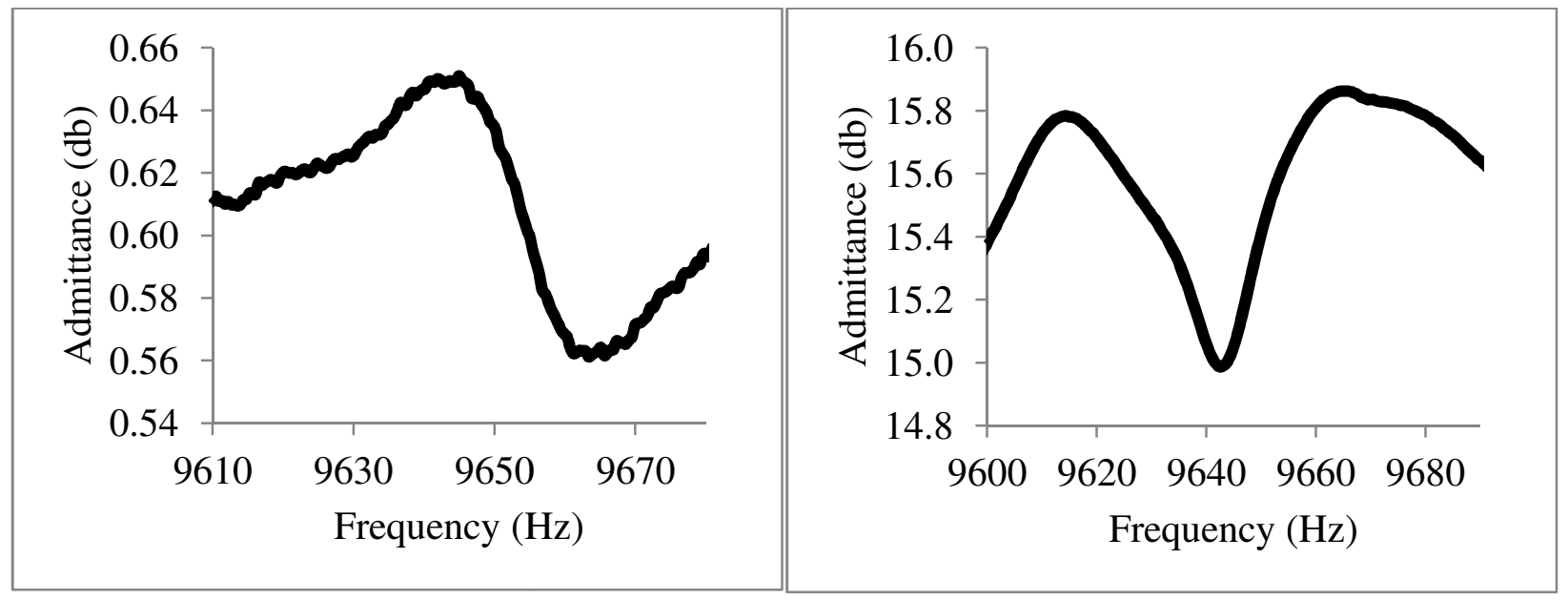

Figure 28a RC Circuit Admittance

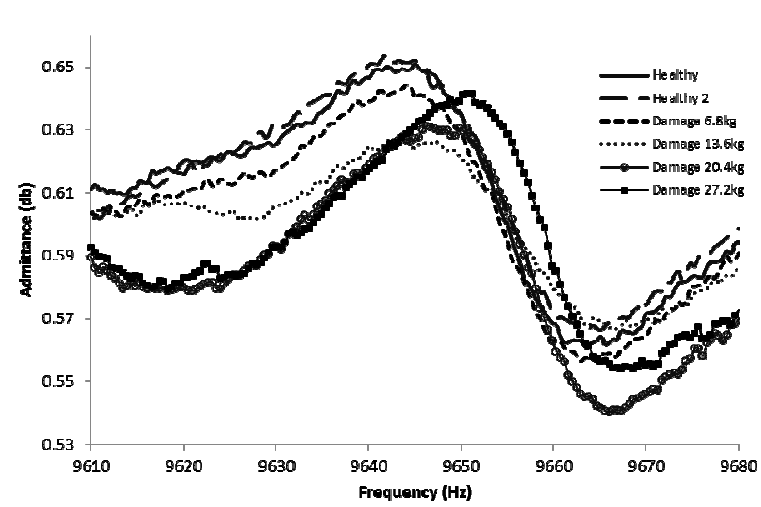

Figure 28b RLC Circuit Admittance

Table 6. RC Case 1 NRD Values

\begin{tabular}{|l|c|c|}
\hline $\begin{array}{l}\text { Frequency Range } \\
(\mathrm{Hz})\end{array}$ & $9610-9680$ & $9630-9660$ \\
\hline$\Delta \mathrm{w}(\mathrm{Hz})$ & 70 & 30 \\
\hline Healthy 2 & .004 & .003 \\
\hline Damage 6.8kg & .006 & .006 \\
\hline Damage 13.6kg & .013 & .017 \\
\hline Damage 20.4kg & .024 & .018 \\
\hline Damage 27.2kg & .024 & .024 \\
\hline
\end{tabular}

Figure 29. RC Case 1 
Each damaged response alters the curve more than the threshold healthy response, indicating that the PZT can indeed determine the difference between temperature and environmental effects on the rail and damage to the rail. In addition, as the mass increases, the total change from the healthy admittance curve to the damaged curve increases. For example, the $20.4 \mathrm{~kg}$ curve deviates further from the healthy response than the $6.8 \mathrm{~kg}$ curve. Therefore, the PZT has the ability to recognize the magnitude of damage on the rail section at a given location. This particular result also shows the importance of quantifying the total difference between two curves in terms of both NRD values with different frequency ranges. If only the larger frequency range was used, there would be no apparent difference between $20.4 \mathrm{~kg}$ of damage and $27.2 \mathrm{~kg}$ of damage. If only the smaller range was used however, there would be little difference between $13.6 \mathrm{~kg}$ of damage and $20.4 \mathrm{~kg}$ of damage. However, looking at both NRD values simultaneously, one can see that the total change o the admittance curve for $20.4 \mathrm{~kg}$ of damage lies somewhat between the total change of $13.6 \mathrm{~kg}$ and that of $27.2 \mathrm{~kg}$.

The previous experiment is then repeated for the RLC case with a tuned inductance of $.0382 \mathrm{H}$. The damaged results, as well as the second healthy response (Healthy 2 ), are shown in Figure 30 . The healthy responses slightly differ again, with the additional variable being the effect of temperature on inductor performance. The NRD values for the second healthy response and each damaged case is shown in Table 7. The NRD values for the RLC case are significantly larger than the NRD values for the simple RC case. This magnification gives us the ability to more accurately determine the difference between environmental effects and small sized damage on the rail section. Again, for the same damage under identical excitation, the more the admittance curve changes, the higher the sensitivity of the sensor [9]. For the RC case, the 
difference in NRD values between the healthy response and $6.8 \mathrm{~kg}$ damaged response is .002 . In comparison, the difference for the RLC case is .026 , which is a thirteen times increase. For both cases, as weight increases, the total change from the healthy admittance curve to the damaged curve increases. However, with the integration of inductive circuitry, the change from one damaged response to another is amplified. This increases the overall sensitivity of the sensor and aids in determining the exact magnitude of small sized damage on the rail section.

Table 7. RLC Case 1 NRD Values

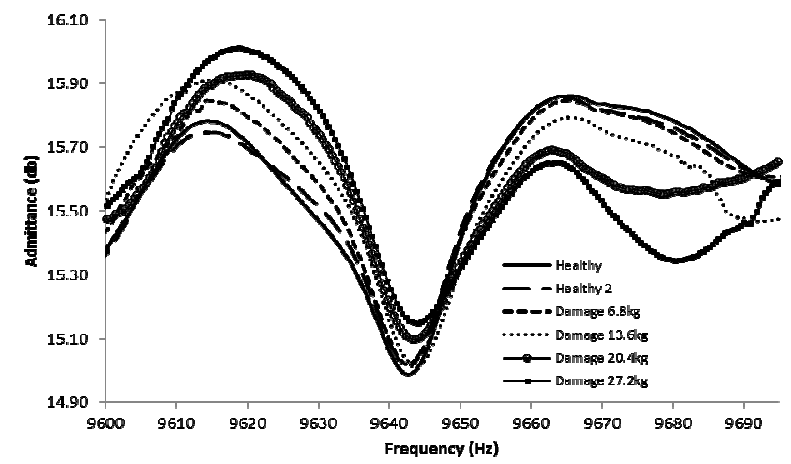

\begin{tabular}{|l|c|c|}
\hline $\begin{array}{l}\text { Frequency Range } \\
(\mathrm{Hz})\end{array}$ & $9610-9680$ & $9630-9660$ \\
\hline$\Delta \mathrm{w}(\mathrm{Hz})$ & 70 & 30 \\
\hline Healthy 2 & .023 & .026 \\
\hline Damage 6.8kg & .049 & .042 \\
\hline Damage 13.6kg & .111 & .098 \\
\hline Darliage 20.4kg & .178 & .141 \\
\hline Damage 27.2kg & .248 & .181 \\
\hline
\end{tabular}

Figure 30. RLC Case 1

Next, a set of damaged responses are taken by setting a constant weight of $27.2 \mathrm{~kg}$ and varying the location of the damage along the rail from the right side of the sensor. Damage is placed at $1 \mathrm{~m}, 2 \mathrm{~m}, 2.5 \mathrm{~m}$ (the edge of rail section), and at $4 \mathrm{~m}$, where $4 \mathrm{~m}$ crosses the joint of the 
test rail section to the adjacent section. The reason behind placing damage on the adjacent rail section is to determine if the sensor could detect damage across joint connections between two rail sections. For the $\mathrm{RC}$ case, the damaged results, and the original healthy response (for reference) are shown in Figure 31.

Table 8. RC Case 2 NRD Values

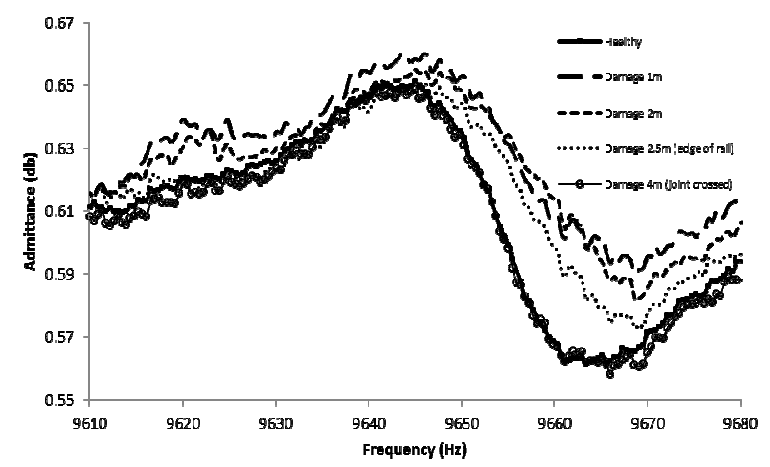

\begin{tabular}{|l|c|c|}
\hline \multicolumn{1}{|c|}{$\begin{array}{c}\text { Frequency } \\
\text { Range }(\mathrm{Hz})\end{array}$} & $9610-9680$ & $9630-9660$ \\
\hline$\Delta \mathrm{w}(\mathrm{Hz})$ & $\mathrm{N})$ & 30 \\
\hline Healthy & .004 & .003 \\
\hline Damage $1 \mathrm{~m}$ & .018 & .017 \\
\hline Damage $2 \mathrm{~m}$ & .014 & .014 \\
\hline Damage 2.5m & .008 & .010 \\
\hline "Damage 4m & .003 & .002 \\
\hline
\end{tabular}

Figure 31. RC Case 2

As seen in Figure 31, the location of damage directly affects the magnitude of the admittance curve change from the healthy response. As damage is moved further away from the sensor, the difference between the damaged curve and the healthy curve decreases. At $4 \mathrm{~m}$, when the rail joint is crossed, the damaged response closely resembles the healthy response, within base noise of the circuit. These trends are reflected in the NRD values of each case, shown in Table 8. For reference, the healthy threshold NRD value is the identical value used in the previous experiment for the RC circuit, as it was taken after all damaged cases. It can be seen that at $1 \mathrm{~m}$, the overall difference between the healthy and damaged curve is the greatest. This difference steadily decreases as the damage moves farther away from the sensor. This shows that the PZT has the potential ability to determine at what location along the rail section damage is present. The PZT can clearly discern the difference between damage at $2 \mathrm{~m}$ and at $2.5 \mathrm{~m}$, yielding 
a higher level of health monitoring accuracy. At 4m, when the joint is crossed into the new rail section, the NRD value dips below the threshold value for a healthy response. Therefore, the PZT is no longer able to detect the presence of damage. This is primarily due to the inability of the PZT to excite the adjacent rail through the joint.

The previous experiment is repeated with industry circuitry to see the effects of inductive circuitry on damage detection range. The damaged results, as well as the original healthy response (for reference), are shown in Figure 32 with corresponding NRD values in Table 9. Once again, the integration of inductive circuitry enhances the ability to discern between environmental effects and small sized damage on the rail section, and amplifies the change from one damaged response to another. A shift in damage from one location to another along the rail section is clearly indicated by the drastic admittance curve changes around resonance and NRD value differences. The key finding though is that through this magnification, inductive circuitry has the ability to increase the range at which the sensor can detect small-sized damage. This can be seen by observing the NRD values both with and without inductive circuitry at $2.5 \mathrm{~m}$, right before the join is crossed into the next rail section. Without inductive circuitry, the NRD value is approximately three times the threshold value for a healthy response. With inductive circuitry however, the NRD value is approximately ten times the threshold value for a healthy response. This alludes to the significant increase in sensor detection range with the integration of inductive circuitry.

Table 9. RLC Case 2 NRD Values 


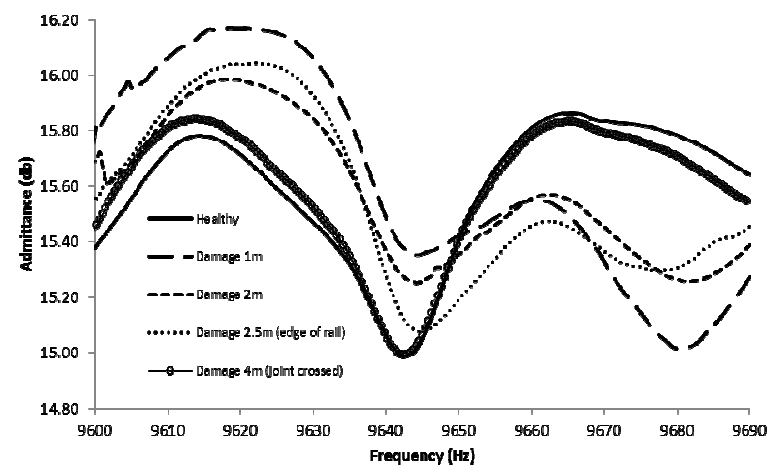

\begin{tabular}{|l|c|c|}
\hline $\begin{array}{l}\text { Frequency } \\
\text { Range }(\mathrm{Hz})\end{array}$ & $9610-9680$ & $9630-9660$ \\
\hline$\Delta \mathrm{w}(\mathrm{Hz})$ & 10 & 30 \\
\hline Healthy & .023 & .026 \\
\hline Damage $1 \mathrm{~m}$ & .417 & .317 \\
\hline Damage $2 \mathrm{~m}$ & .337 & .263 \\
\hline Damage $2.5 \mathrm{~m}$ & .289 & .235 \\
\hline *Damage $4 \mathrm{~m}$ & .039 & .020 \\
\hline
\end{tabular}

Figure 32. RLC Case 2

\section{RESULTS AND CONCLUSIONS}

In this thesis, an impedance-based based damage detection method using piezoelectric transducers is validated as a solution for real-time railway health monitoring. Hamilton's Principle is utilized to derive the transducer-rail coupled equations of motion and resulting impedance/admittance response. The setback of low signal-to-noise ratio in the admittance response is alleviated with the integration of tuned inductive circuitry, which creates an electrical resonant effect that, when aligned with the rail's mechanical resonance, amplifies the admittance response and increases damage detection sensitivity.

Several preliminary investigations are carried out in a lab setting to demonstrate the feasibility of the damage detection method; a fixed-fixed aluminum strip beam, a railway segment, and a large stainless steel beam. A comprehensive MatLab program is developed to numerically validate the admittance responses on the strip beam, and an ANSYS finite element analysis is created to provide insight as to the mode shapes of a 3-D railway. In each investigation, the PZT is able to detect the presence of damage by a change in the healthy 
admittance curve to an altered-damaged curve. In addition, inductive circuitry proved to increase overall performance in alignment with the derived theory.

Because of the positive preliminary investigations, the damage detection method is then implemented on an in-use test railway track. A Normalized Relative Difference Outlier Analysis is employed to discern the difference between damage to the rail and temperature or environmental changes. The damage detection method is successful in detecting damage with different profiles on the rail section. The integration of inductive circuitry greatly increases the magnitude of the admittance curves, and when properly tuned, magnifies the admittance change at resonance. This leads to an increase in signal-to-noise ratio and overall performance improvement, specifically in the damage detection range of the sensor. From these promising results, the conclusion is that an impedance-based SHM system utilizing piezoelectric transducers has the potential ability to fulfill the need to detect small sized damage in real-time on the railway track.

This research is supported by the Department of Homeland Security. I would like to thank Sperry Rail Services for providing a test rail and related equipment. 


\section{APPENDIX}

\subsection{Winkler Foundation Derivation}

A Winkler Foundation is a uniform elastic foundation made of a material that follows Hooke's Law. Therefore, a unit deflection (y) in the beam will cause a reaction force $(\mathrm{R})$ in the foundation as shown:

$$
\mathrm{R}(\mathrm{x})=\mathrm{k}_{\mathrm{w}} \mathrm{y}(\mathrm{x})
$$

where $\mathrm{k}_{\mathrm{w}}$ is the modal foundation stiffness. For free vibration, $\mathrm{y}(\mathrm{x})$ becomes $\mathrm{q}$, which transforms (A1) into:

$$
\mathrm{F}_{\mathrm{w}}=\mathrm{k}_{\mathrm{w}} \mathrm{q}
$$

Following Hamilton's Principle, the potential energy of the rail is now the sum of the stand-alone potential energy of the rail and the potential energy of the foundation. Using the assumed mode method as previously discussed, the new potential energy is:

$$
\mathrm{U}_{\mathrm{rw}}=\mathrm{U}_{\mathrm{r}}+\mathrm{U}_{\mathrm{w}}=\frac{1}{2} \mathrm{k}_{\mathrm{r}} \mathrm{q}^{2}+\frac{1}{2} \mathrm{k}_{\mathrm{w}} \mathrm{q}^{2}
$$


The kinetic energy of the rail and the potential energy of the piezo transducer are both safely assumed to be unaffected by the foundation. However, the virtual work on the railway, $\delta \mathrm{W}_{\mathrm{v}}$, is affected by the additional structural damping caused by the foundation. By again assuming free vibration, the total damping can be found as the sum of the rail's damping and foundation damping. Using the same derivation process as in 4.1, the modified equations of motion to account for the Winkler Foundation are found below:

$$
\begin{aligned}
& \mathrm{m} \ddot{\mathrm{q}}+\left(\mathrm{g}_{\mathrm{r}}+\mathrm{g}_{\mathrm{w}}\right) \dot{\mathrm{q}}+\left(\mathrm{k}_{\mathrm{r}}+\mathrm{k}_{\mathrm{w}}\right) \mathrm{q}+\mathrm{k}_{1} \mathrm{Q}=\mathrm{F}_{\mathrm{m}} \\
& \mathrm{k}_{2} \mathrm{Q}+\mathrm{k}_{1} \mathrm{q}=\mathrm{V}_{\mathrm{a}}
\end{aligned}
$$

Because the integration of the Winkler Foundation causes the total structural stiffness to increase, the natural frequencies of the rail will increase. Additional damping renders a lower level of performance, with a reduction in the amplification of the structural dynamic response. This results in the flattening of the admittance peak at resonance and a loss of damage detection sensitivity.

\subsection{Inductance Tuning Formulation}

Note: This work is based upon previous work performed by X. Wang and J. Tang [9].

The admittance change due to damage (causing a change in structural stiffness) is:

$$
\Delta \widehat{\mathrm{Y}}_{\mathrm{LN}}=\frac{\widehat{\mathrm{P}}_{\mathrm{L}}}{\widehat{\mathrm{Y}}_{\mathrm{P}}}-\frac{\widehat{\mathrm{Y}}_{\mathrm{L}}}{\widehat{\mathrm{Y}}_{\mathrm{P}}}=\frac{\mathrm{k}_{2}\left(-\mathrm{mw} \mathrm{w}^{2}+\mathrm{icw}+\mathrm{k}\right)}{\left(-\mathrm{L} \mathrm{w}^{2}+\mathrm{iRw}+\mathrm{k}_{2}\right)\left(-\mathrm{mw}^{2}+\mathrm{icw}+\mathrm{k}\right)-\mathrm{k}_{1}^{2}}-\frac{\mathrm{k}_{2}\left(-\mathrm{mw} \mathrm{w}^{2}+\mathrm{icw}+\mathrm{k}-\Delta \mathrm{k}\right)}{\left(-\mathrm{L} \mathrm{w}^{2}+\mathrm{iRw}+\mathrm{k}_{2}\right)\left(-\mathrm{mw} \mathrm{w}^{2}+\mathrm{icw}+\mathrm{k}-\Delta \mathrm{k}\right)-\mathrm{k}_{1}^{2}}
$$

Where $\widetilde{\widehat{Y}_{L}}$ is the normalized admittance of the damaged rail with inductive circuitry, and $\Delta \mathrm{k}$ is the equivalent rail stiffness change. The admittance change without the inductor is similarly found by setting the inductance and resistance of the inductor to zero. Because the circuitry 
admittance difference $\Delta \widehat{\mathrm{Y}}_{\mathrm{LN}}$ is a non-linear function of the equivalent stiffness change $\Delta \mathrm{k}$, a Taylor series expansion is used to determine the relationship between $\Delta \widehat{\mathrm{Y}}_{\mathrm{LN}}$ and $\Delta \mathrm{k}$, which can yield the optimal inductance value for any damaging case. Using the Taylor Series Expansion, the normalized circuitry admittance is transformed as follows:

$$
\begin{aligned}
& \Delta \widehat{\mathrm{Y}}_{\mathrm{LN}}(\Delta \mathrm{k}) \approx \Delta \widehat{\mathrm{Y}}_{\mathrm{LN}}(\Delta \mathrm{k}=0)+\left.\frac{\partial \Delta \widehat{\mathrm{Y}}_{L N}}{\partial \Delta \mathrm{k}}\right|_{\mathrm{k}=0} \Delta \mathrm{k}=\frac{\mathrm{k}_{2} \mathrm{k}_{1}^{2}}{\left[\left(-\mathrm{L} \mathrm{w}^{2}+\mathrm{iR} \mathrm{w}+\mathrm{k}_{2}\right)\left(-\mathrm{m} \mathrm{w}^{2}+\mathrm{ic} \mathrm{w}+\mathrm{k}\right)-\mathrm{k}_{1}^{2}\right]^{2}} \Delta \mathrm{k}= \\
& \delta \widehat{\mathrm{Y}}_{\mathrm{LN}}(\mathrm{w}) \Delta \mathrm{k}
\end{aligned}
$$

Where the sensitivity is defined as:

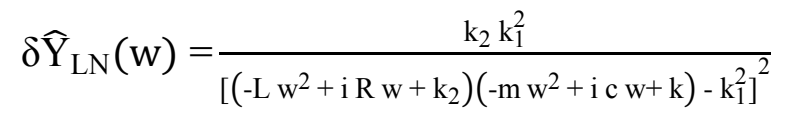

Optimal inductance tuning is defined as equating the magnitude of the two peaks in the admittance curve, which means that the overall amplification effect is balanced. This results in a maximization of the frequency range at which the admittance is amplified, and it increases that admittance curve change at resonance. Using the definition of sensitivity, the procedure to optimize the inductance at a given resonant frequency is as follows:

(1) Choose an initial inductance value $\left(\mathrm{k}_{2} \frac{\mathrm{m}}{\mathrm{k}}\right)$, that results in a natural frequency that is equal to the natural frequency of the mechanical structure.

(2) Observe the two peak frequencies in the $\left|\delta \widehat{\mathrm{Y}}_{\mathrm{LN}}(\mathrm{w})\right|$ curve and evaluate the sign of $\left|\delta \widehat{\mathrm{Y}}_{\mathrm{LN}}\left(\mathrm{w}_{\mathrm{j}}\right)\right|-\left|\delta \widehat{\mathrm{Y}}_{\mathrm{LN}}\left(\mathrm{w}_{\mathrm{j}-1}\right)\right|$ in the frequency range around resonance. If the sign changes, a root exists between $\mathrm{w}_{\mathrm{j}-2}$ and $\mathrm{w}_{\mathrm{j}}$. 
(3) Assign $w_{m}$ and $w_{n}$ as the two peak frequencies, with corresponding magnitudes $\left|\delta \widehat{Y}_{L N}\left(w_{m}\right)\right|$ and $\left|\delta \widehat{Y}_{L N}\left(w_{n}\right)\right|$, respectively. If the absolute value of their difference, $\left\|\delta \widehat{Y}_{L N}\left(w_{m}\right)|-| \delta \widehat{Y}_{L N}\left(w_{n}\right)\right\|$, is less than a pre-set small positive value $(\square)$, the optimal inductance value has been found.

Otherwise, increase the inductance value and repeat steps (2) and (3), until $\| \delta \widehat{\mathrm{Y}}_{\mathrm{LN}}\left(\mathrm{w}_{\mathrm{m}}\right) \mid-$ $\left|\delta \widehat{\mathrm{Y}}_{\mathrm{LN}}\left(\mathrm{w}_{\mathrm{n}}\right)\right| \mid<\square$.

\subsection{Aluminum Strip Beam Frequency Comparison}

The theoretical natural frequency equation for a beam is defined as:

$$
\mathrm{f}_{\mathrm{o}}=\left(\frac{\square}{2 \Pi}\right)^{2} \sqrt{\frac{\mathrm{EI}}{\rho \mathrm{AL}^{4}}}
$$

Where $\square$ is the mode parameter, E is Young's modulus, I is the area moment of inertia, L is the length of the beam, and $\mathrm{m}$ is the mass per unit length of beam. For a fixed-fixed beam, the equation to determine $\square$ is:

$$
\square=\frac{(2 \mathrm{n}+1)}{2}
$$

Where $\mathrm{n}$ is the mode of operation. At each mode, the corresponding theoretical natural frequency can be obtained to a satisfactory degree of accuracy. 


\begin{tabular}{|c|c|c|c|}
\hline Order & Theoretical (Hz) & MatLab Model (Hz) & Experimental (Hz) \\
\hline 1 & 43.85 & 42.90 & 44.10 \\
\hline 2 & 120.9 & 121.4 & 124.3 \\
\hline 3 & 236.9 & 238.6 & 237.1 \\
\hline 4 & 391.7 & 395.9 & 395.2 \\
\hline 5 & 585.2 & 586.5 & 590.4 \\
\hline 6 & 817.2 & 820.3 & 826.4 \\
\hline 7 & 1,088 & 1,091 & 1,098 \\
\hline 8 & 1,397 & 1,410 & 1,413 \\
\hline 9 & 1,745 & 1,759 & 1,763 \\
\hline 10 & 2,132 & 2,142 & 2,154 \\
\hline
\end{tabular}

\subsection{Finite Element Model Trials}




\begin{tabular}{|c|c|c|c|c|c|c|c|}
\hline & $\begin{array}{c}\text { Trial } 1 \\
(34,100 \\
\text { elements })\end{array}$ & $\begin{array}{c}\text { Trial } 2 \\
(99,500 \\
\text { elements })\end{array}$ & $\begin{array}{c}\text { Percent } \\
\text { Difference } \\
1,2\end{array}$ & $\begin{array}{c}\text { Trial } 3 \\
(211,400 \\
\text { elements) }\end{array}$ & $\begin{array}{c}\text { Percent } \\
\text { Difference } \\
2,3\end{array}$ & $\begin{array}{c}\text { Trial } 4 \\
(273,600 \\
\text { elements })\end{array}$ & $\begin{array}{c}\text { Percent } \\
\text { Difference } \\
3,4\end{array}$ \\
\hline Mode & $\begin{array}{c}\text { Frequency } \\
\text { (Hz) }\end{array}$ & $\begin{array}{c}\text { Frequency } \\
\text { (Hz) }\end{array}$ & $\%$ & $\begin{array}{c}\text { Frequency } \\
\text { (Hz) }\end{array}$ & $\%$ & $\begin{array}{c}\text { Frequency } \\
\text { (Hz) }\end{array}$ & $\%$ \\
\hline 1 & 0 & 0 & $0.00 \% *$ & 0 & $0.00 \% *$ & 0 & $0.00 \% *$ \\
\hline 2 & $3.12 \mathrm{E}-33$ & $5.04 \mathrm{E}-04$ & $100.00 \%$ & $1.68 \mathrm{E}-03$ & $69.95 \%$ * & $2.15 \mathrm{E}-03$ & $21.96 \%$ * \\
\hline 3 & $6.70 \mathrm{E}-04$ & $1.18 \mathrm{E}-03$ & $43.18 \%$ & $1.86 \mathrm{E}-03$ & $36.76 \%$ & $2.18 \mathrm{E}-03$ & $14.46 \%$ \\
\hline 4 & 435.87 & 434.2 & $0.38 \%$ & 433.58 & $0.14 \%$ & 433.35 & $0.05 \%$ \\
\hline 5 & 1126.5 & 1118.6 & $0.71 \%$ & 1115.7 & $0.26 \%$ & 1115.2 & $0.04 \%$ \\
\hline 6 & 2817.1 & 2789.1 & $1.00 \%$ & 2780.9 & $0.29 \%$ & 2778.5 & $0.09 \%$ \\
\hline 7 & 3276.8 & 3279 & $0.07 \%$ & 3281.2 & $0.07 \%$ & 3281.1 & $0.00 \%$ \\
\hline 8 & 3355.1 & 3349 & $0.18 \%$ & 3360.5 & $0.34 \%$ & 3358.8 & $0.05 \%$ \\
\hline 9 & 4489.2 & 4463.9 & $0.57 \%$ & 4455.7 & $0.18 \%$ & 4453.9 & $0.04 \%$ \\
\hline 10 & 4767.8 & 4761.3 & $0.14 \%$ & 4782.8 & $0.45 \%$ & 4780.4 & $0.05 \%$ \\
\hline 11 & 4828.5 & 4821.1 & $0.15 \%$ & 4841.5 & $0.42 \%$ & 4838.7 & $0.06 \%$ \\
\hline 12 & 5900.5 & 5891.3 & $0.16 \%$ & 5893 & $0.03 \%$ & 5891.9 & $0.02 \%$ \\
\hline 13 & 6425.9 & 6418.6 & $0.11 \%$ & 6422.6 & $0.06 \%$ & 6421.4 & $0.02 \%$ \\
\hline 14 & 6883 & 6876.5 & $0.09 \%$ & 6877.5 & $0.01 \%$ & 6876.5 & $0.01 \%$ \\
\hline 15 & 7216.7 & 7177 & $0.55 \%$ & 7166.5 & $0.15 \%$ & 7163.5 & $0.04 \%$ \\
\hline 16 & 8558.7 & 8557.1 & $0.02 \%$ & 8564.6 & $0.09 \%$ & 8563.7 & $0.01 \%$ \\
\hline 17 & 8610.8 & 8589.2 & $0.25 \%$ & 8594 & $0.06 \%$ & 8591.6 & $0.03 \%$ \\
\hline 18 & 9053.2 & 8930.4 & $1.38 \%$ & 8894.7 & $0.40 \%$ & 8886.3 & $0.09 \%$ \\
\hline 19 & 9185.4 & 9077.6 & $1.19 \%$ & 9049.2 & $0.31 \%$ & 9041.8 & $0.08 \%$ \\
\hline 20 & 9321.5 & 9313.4 & $0.09 \%$ & 9338.3 & $0.27 \%$ & 9335 & $0.04 \%$ \\
\hline 21 & 9476.1 & 9459.8 & $0.17 \%$ & 9455.5 & $0.05 \%$ & 9454.1 & $0.01 \%$ \\
\hline 22 & 9752.2 & 9725.6 & $0.27 \%$ & 9722.7 & $0.03 \%$ & 9719.5 & $0.03 \%$ \\
\hline 23 & 10283 & 10240 & $0.42 \%$ & 10240 & $0.00 \%$ & 10236 & $0.04 \%$ \\
\hline 24 & 10908 & 10812 & $0.89 \%$ & 10784 & $0.26 \%$ & 10777 & $0.06 \%$ \\
\hline 25 & 12346 & 12332 & $0.11 \%$ & 12336 & $0.03 \%$ & 12333 & $0.02 \%$ \\
\hline \multirow{2}{*}{\multicolumn{2}{|c|}{$\begin{array}{l}\text { *Rigid body modes, } \\
\text { disregard percentage } \\
\text { differences }\end{array}$}} & $\begin{array}{c}\text { Max \% } \\
\text { Difference }\end{array}$ & $1.38 \%$ & & $.45 \%$ & & $.09 \%$ \\
\hline & & $\begin{array}{l}\text { Average \% } \\
\text { Difference }\end{array}$ & .4096 & & $.18 \%$ & & $.04 \%$ \\
\hline
\end{tabular}

\section{REFERENCES}


[1] Method of and an apparatus for in situ ultrasonic rail inspection of a railroad rail, Sperry Rail Company, http://www.sperryrail.com/home.html.

[2] Clark, R., 2003. "Rail flaw detection: overview and needs for future developments," NDT\&E International, 37:111-118.

[3] Bruzelius, K. and Mba, D., 2003, "An initial investigation on the potential applicability of Acoustic Emission to rail track fault detection,” NDT\&E International, 37:507-516.

[4] Rose, J.L., 2000, "Elastic Wave Analysis for Broken rail detection,” NDT article idn270.

[5] Rose, J. L., Avioli, M. J., Mudge, P., and Sanderson, R., 2004, "Guided wave inspection potential of defects in rail" NDT\&E International, 37:153-161.

[6] Loveday, P.W., 2000, "Development of piezoelectric transducers for a railway integrity monitoring system,” Proceedings of SPIE, 3988:330-338.

[7] Tang, J., and Wang, KW., 2001, "Active-Passive Hybrid Piezoelectric Networks for Vibration Control: Comparisons and Improvement" Journal of Intelligent Material Systems and Structures, 10:794-806.

[8] Wang, X., and Tang, J., 2009, "Damage Identification using Piezoelectric Impedance Approach and Spectral Element Method," Journal of Intelligent Material Systems and Structures, 20:907-921.

[9] Wang, X., and Tang, J., 2010, "Damage Detection Using Piezoelectric Admittance Approach with Inductive Circuitry,” Journal of Intelligent Material Systems and Structures, 21: 667.

[10] Rosiek, M., Martowicz, A., and Uhl, T., 2012, "An Overview of Electromechanical Impedance Method for Damage Detection in Mechanical Structures," Structural Health Monitoring, Vol. 2. 
[11] Park, G., Sohn, H., Farrar, C.R., and Inman, D.J., 2003, "Overview of Piezoelectric Impedance-Based Health Monitoring and Path Forward," Shock and Vibration Digest, 35:451463.

[12] Park, G., Farrar, C. R., Lanza di Scalea, F., and Coccia S., 2006, "Performance Assessment and Validation of Piezoelectric Active-Sensors in Structural Health Monitoring," Smart Materials and Structures, 15:1673-1683.

[13] Park, S., Inman, D.J., and Yun, C.-B., 2008, "An outlier analysis of MFC-based impedance sensing data for wireless structural health monitoring of railroad tracks," Engineering Structures, 30:2792-2799.

[13] Wang, K.W., and Tang, J., 2008, Adaptive Structural Systems with Piezoelectric Transducer Circuitry, Springer Publications.

[14] Zang C., Friswell M.I., and M. Imregun., 2003, "Structural Health Monitoring and Damage Assessment Using Measured FRFs from Multiple Sensors, Part I: The Indicator of Correlation Criteria,” Trans Tech Publications, Switzerland.

[15] Zhao J., Wang X., Tang, J., 2011, "Damping Reduction in Structures Using Piezoelectric Circuitry with Negative Resistance", Journal of Vibration and Acoustics, Vol. 133/ 041009-1.

[16] Zhao J., Tang J., and Wang, KW., 2011, “Anomaly amplification for damage detection of periodic structures via piezoelectric transducer networking", Smart Materials and Structures, 20: 105006.

[17] Zhao, J., and Tang, J., 2013, “Amplifying damage signature in periodic structures using enhanced piezoelectric networking with negative resistance elements," Journal of Intelligent Material Systems and Structures, 24: 1613-1625. 
[18] Tang J, Wang K W, and Philen, M, 1999, "Sliding mode control of structural vibrations via active-passive hybrid piezoelectric network", Proc. SPIE, Smart Structures, 3668: 543-554 [19] Agnes, G. S., 1994, “Active/passive piezoelectric vibration suppression”, Proc. SPIE, Smart Structures, 2193: 24-34

[20] Anton, S. R. and Sodano, H. A, 2007, “A review of power harvesting using piezoelectric materials", 2003-2006, Smart Materials and Structures, 16: R1-21

[21] Hsu, M. H., 2009, "Vibration Analysis of Non-Uniform Beams Resting on Elastic Foundations Using the Spline Collocation Method", Tamkang Journal of Science and Engineering, Vol. 12, No. 2: 113-122

[22] Zou, Y., Tong, L. and Steven, G.P., 2000, “Vibration-based Model-dependent Damage (Delamination) Identification and Health Monitoring for Composite Structures - A Review', Journal of Sound and Vibration, 230: 357-378.

[23] Doebling, S. W., Farrar, C. R., and Prime, M. B., 1998, “A Summary Review of Vibration-Based Damage Identification Methods”, Shock Vibration Digest, 30: 91-105

[24] Barke, D. and Chiu W. K., 2005, "Structural Health Monitoring in the Railway Industry: A Review”, Structural Health Monitoring, Vol. 4, No. 1: 81-93

[25] Li, Jingcheng, Jang, S and Tang, J., 2013, “Optimization of piezoelectric energy harvester for wireless smart sensors in railway health monitoring", Proc. SPIE Smart Structures, 8692Structures

[26] Fukunagaa, Hisao, Hua, N., and Chang, F. K., 2002, "Structural damage identification using piezoelectric sensors", International Journal of Solids and Structures, Volume 39, Issue 2: 393 418 